Portland State University

PDXScholar

$1-1-2011$

\title{
Working in an Artist Collective in Portland Oregon: \\ The artistic benefits of cooperation and place in an underground art world
}

Elizabeth Furlong Borders

Portland State University

Follow this and additional works at: https://pdxscholar.library.pdx.edu/open_access_etds

Let us know how access to this document benefits you.

\section{Recommended Citation}

Borders, Elizabeth Furlong, "Working in an Artist Collective in Portland Oregon: The artistic benefits of cooperation and place in an underground art world" (2011). Dissertations and Theses. Paper 188. https://doi.org/10.15760/etd.188

This Thesis is brought to you for free and open access. It has been accepted for inclusion in Dissertations and Theses by an authorized administrator of PDXScholar. Please contact us if we can make this document more accessible: pdxscholar@pdx.edu. 
Working in an Artist Collective in Portland Oregon: The artistic benefits of cooperation and place in an underground art world

by

Elizabeth Furlong Borders

A thesis submitted in partial fulfillment of the requirements for the degree of

\author{
Master of Science \\ in \\ Sociology \\ Thesis Committee: \\ Robert Liebman, Chair \\ Martha Balshem \\ Veronica Dujon \\ Harrell Fletcher \\ Portland State University \\ (C2012
}




\begin{abstract}
This ethnography explores the underground art world in Portland, Oregon by showing how a Portland area artist collective, Oregon Painting Society, navigates their art world. Participant observation, in-depth interviews, and a short latent content analysis triangulate data to show the features and values of the underground art world. Using Becker's concept of art worlds, I show how artists working outside of a traditional art career in a commercial gallery system do their work by exploring how Portland's art world is structured and sustained. I find that group work, cooperation, and resource sharing in a vibrant neighborhood based social network enables artists to substitute resources usually provided by gallery representation and sustain their ability to make artwork without financial support. This is a network that rejects the competitive structure of the commercial system and runs more smoothly the more artists participate in it. I also explore the reasons for Portland's particular ability to support this kind of environment, citing geographic proximity to other art cities, DIY cultural roots, neighborhood structure, affordable city amenities, and a creative class population.
\end{abstract}


Dedication:

To the artists who inspire me every day. You know who you are. 


\section{Acknowledgements:}

Thanks so much to Oregon Painting Society working with me, to Bob Liebman for patient advice often way past normal working hours, and to Jason for enduring my thesis storm. 
ABSTRACT. . $\mathrm{i}$

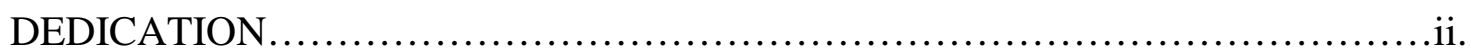

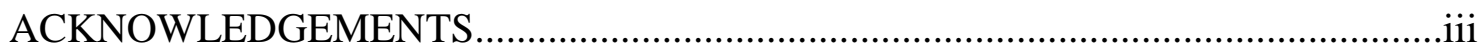

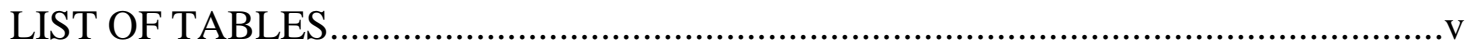

LIST OF FIGURES ............................................................

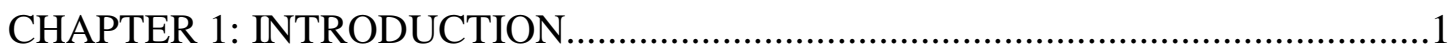

CHAPTER 2: THE CASE, PORTLAND AND OPS..................................................

CHAPTER 3: LITERATURE REVIEW AND THEORY ............................................22

CHAPTER 4: METHODS, ETHNOGRAPHIC CASE STUDY ....................................43

CHAPTER 5: FINDINGS PART ONE, ARTISTIC AND SOCIAL RESOURCES IN THE COLLECTIVE........................................................57

CHAPTER 6: FINDINGS PART 2, VALUES AND THE UNDERGROUND ART

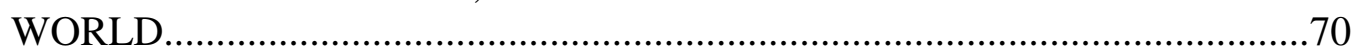

CHAPTER 7: FINDINGS PART 3, THE ESTABLISHED ART WORLD...................90

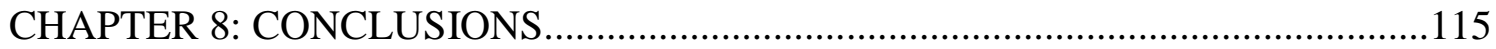

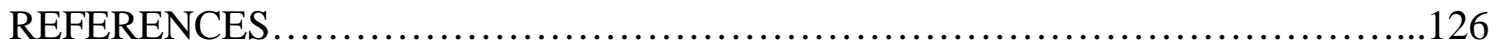

APPENDIX A: ARTIST COLLECTIVE INTERVIEW GUIDE....................................131

APPENDIX B: ART VENUE INTERVIEW GUIDE.................................................133

APPENDIX C: PARTICIPANT OBSERVATION CONSENT FORM.........................134

APPENDIX D: COLLECTIVE MEMBER INTERVIEW CONSENT FORM.............136

APPENDIX E: ART VENUE INTERVIEW CONSENT FORM..................................138 


\section{LIST OF TABLES}

TABLE 1: Two Art Worlds Compared....................................96 


\section{LIST OF FIGURES}

FIGURE 1: The Commercial Gallery System...........................26

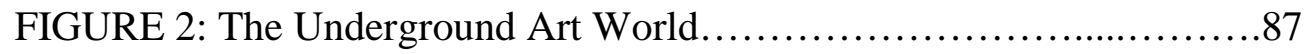

FIGURE 3: The Continuum Between the Established and the Underground Art

Worlds................................................................... 100 


\section{CHAPTER ONE: INTRODUCTION}

The thought of studying artist collectives grew out of my experience with artists who had graduated from an art school in Columbus, OH. My husband is a working artist who attended Columbus College of Art and Design and my social circle at that time consisted mostly of artists. As an outsider, meaning one who does not produce art, but well integrated into an artistic circle, I was struck by the difficulties many of my friends experienced as recent graduates making art. Many could not find jobs, and some eventually moved home to live with their parents. However, I noticed that those who chose to work with each other continued to produce and show work with consistency.

During the same time, I heard from many friends and acquaintances that Portland, Chicago, or Brooklyn were places that artists should go if they wanted to make art. Through word of mouth, a migration took place in my social circle. Many recent graduates began moving to cities because of their art scene- my husband and I chose Portland for its reputation as an art city, its graduate sociology program, reasonable size, good public transit, a progressive population of young people, and its location in the beautiful Pacific Northwest.

When we arrived, the reality of the art scene in Portland did not match the hype we had heard. Artists in Portland are not supporting themselves as artists, but rather as servers, baristas, and nannies. However, the art scene, particularly in northeast Portland, is active, fueled by artists who do not make a living doing art. These observations and experiences framed my questions for the thesis. 
I began this project to learn how artists think about making art outside of the traditional career model that they learn in school. I wanted to work with a collective to explore the role of cooperation because of my anecdotal evidence that my friends who chose to work with others were more productive. I also wanted to capture the specific nature of Portland's art scene to understand how place influences artists' ability to make their work. My main research questions are,

1. How do collectives help artists to sustain their artistic practice?

2. How is Portland's underground art world structured and sustained?

3. How is the underground art world sustained by place?

Artists in the underground art world are focus of this research, and my main inquiries are contextualized by curiosity about how the underground art world shapes what being an artist is conceptually and in practice. Thus, an additional frame for this project includes three sub-questions which will be re-visited in the conclusion,

1. Are these artists satisfied with their work environment?

2. Is the lifestyle of underground artists sustainable?

3. Are these artists permanent residents of the underground subcultural world? In other words, do they plan participation in their underground world for the long haul?

Ultimately, the questions I asked are focused around the concept of artistic sustainability, meaning the ability for artists to continue making art. This concept has two main components. First, the artist must have the available resources to make work, meaning supplies, money, and time. The second component of artistic sustainability is the functioning of the larger social system that allows artists to show their work. This component is comprised of audience, venues, and networks. I framed the research in this 
way because I am most interested in learning how artists support themselves through their interactions with each other and with their environment. I found that while work in a collective aided the resources component of artistic sustainability, Portland's favorable underground art scene sustained their ability to show work.

After talking with Harrell Fletcher, artist and professor of the Social Practice of Art program at PSU, I decided that Oregon Painting Society would be a perfect match for this project. A mostly performance and installation based collective, they are fine artists who operate outside of the traditional commercial model by default since their art is not necessarily salable. They were kind enough to agree to participate.

An ethnography, this project seeks to create a valid picture of the world of Portland artist collectives. Many studies about artists study the production of art from the perspective of the places art is sold or shown, likely missing the lived reality of artists by focusing only on the final stage of their work. Instead, I chose to follow artists. I was able to observe an art project from its conception to its installation and learn the process surrounding art making and showing from the artists' perspective. This lens revealed a rich picture of how artists working together navigate their lives and their artistic endeavors through a diversity of venues, audiences, and projects as well as the simultaneous interconnectedness of these elements.

This project is framed using Becker's concept of social worlds, and project seeks to update his theory of Art Worlds to account for technological and cultural changes since the book was written in 1982 by adding the underground art world to his concept and showing its connections to the established art world that he describes as they are navigated by artists. Also, I reorient his theory towards the lived reality of artists rather 
than the places their work appears. By framing the project around a group of artists, I am able to articulate social resources their group provides as part of their Art World, and show how they are employed for making art the same way that Becker describes monetary resources. I also I hope to create a picture of Portland's art scene and explain how it is connected to the larger Art World as a semi-peripheral art city with cultural inclinations and a neighborhood infrastructure to insulate and support emerging artists.

Chapter Two explains the development of Portland's art scene and the case of Oregon Painting Society. Chapter Three reviews the existing literature focusing on Becker's art worlds, Richard Florida's creative class, and Blazak's work on bohemian districts. Chapter Four's findings articulate the benefits of cooperative group work, exploring both the artistic and social resources provided by the collective for its members. Chapter Five discusses the underground art world, and the values that members of OPS hold that help construct the guiding principles of the underground. Chapter Six places the underground and the established art world on a continuum and contrasts the values of each world from the perspective of both artists and the owners of venues where OPS has shown work. I conclude by reviewing the benefits of cooperative artistic behavior and the underground art world and by offering suggestions for art school curricula to help foster cooperative development and awareness of the differences between the established and the underground world.

At the heart of this project is an interest in the well-being of artists and fervor for enabling them to make the incredible work that drives them. It is my hope that this will be read by sociologists and artists alike. For sociologists, I hope this project will shed light on how groups of people have chosen cooperation over competition with their peers 
and sustain their commitment to create a better work outcome for everyone. The underground art world is a testament to prosocial behavior and the human drive to express oneself even in the face of structural barriers. For artists, I hope this account will give you a voice in the social sciences and an additional lens to consider your relationship to the larger world of art so that you might find strength and artistic freedom in cooperation and endurance for competition. 


\section{Chapter 2: THE CASE: PORTLAND AND OPS}

\section{Introduction}

Oregon Painting Society (OPS) is a five person artist collective in Portland Oregon that has membership in the underground art world in their Northeast neighborhood. In order to contextualize the underground art scene in Portland, it is important to trace its roots to DIY (Do It Yourself) punk and grunge music that began in the Pacific Northwest in the 1990s. DIY punk music largely based in Olympia, WA created the regional cultural inclination towards emerging artistic ventures over established, while grunge music, the more popular offshoot of DIY, gave Portland's scene a subcultural identity on a national scale. This established values for the way that music and art gets made, and also established a reason for like-minded people to move to the Pacific Northwest. I argue that the music scene in the Pacific Northwest and the national identity that it created is responsible for establishing the cultural value of DIY that both supports and fuels production in the underground art world in Portland today. The connection between a reputation for music and the development of an art scene is not unusual, and also exists in Chicago's Wicker Park (Lloyd, 2004). The Portland art world exists on a spectrum between two major categories, the established and the underground. The underground art scene reflects the values of the DIY punk/grunge movement, while the established world reflects the values of the national and international art world. This chapter introduces these two worlds.

The established and the underground art world are the social context for Oregon Painting Society (OPS). As Pacific Northwest natives, they are people who have grown up with a DIY cultural identity, most members of OPS being active participants in the 
underground music scene as well. In this chapter, I will provide a description of OPS and a short history of the collective and their members to explain the influence of DIY culture and the case selection.

\section{DIY and Grunge}

During the 1980's and 1990's, Portland became part of a well-known national music scene called grunge that was proliferating in the Pacific Northwest, with many labels based in nearby Seattle. Grunge subculture began as a rejection of punk music. Punk was criticized for becoming too image based, focusing on flashy stage performance and impressive costumes rather than music. The term grunge, coined only after national attention had been focused on the Pacific Northwest, began as a small music movement based mostly in Seattle that valued self-produced small scale lo-fidelity releases, small venue performances, untrained singing and simple guitar chords only slightly altered from common punk chord progression, and causal sloppy dress. (Prey, 1996)

Numerous small record labels with very limited distribution developed such as Sub Pop, PopLlama Records and C/Z Records (Wikipedia g., 2011). They were run as cheaply as possible, most from people's homes. These labels signed many bands in the area. Performances were mostly regional, and most band members did not make a living from the music that they were producing. These bands were somewhat amorphous- many people were members of multiple bands, bands commonly changed names, many faded in and out quickly. (Prey, 1996) This fluid format for creative production still operates in Portland's underground today, and reflects Shorthose and Strange's creative ecology concept discussed in chapter three. It also establishes the development of the subcultural value of self-production as opposed to large scale distribution or the Do it Yourself (DIY) 
ethic. This ethic is still operational in the Portland underground art scene, as discussed in chapter six.

While grunge was an underground scene for many years, the fame of the band Nirvana gave Pacific Northwest national attention. Although this national spotlight resulted in commercial marketing of the grunge image, it also established the Pacific Northwest as subcultural center for small scale music/artistic production. This region of the country became known for grunge music, and also the values that were associated with it. (Prey, 1996) Specifically, the value of DIY has diffused into Portland culture evidenced by local support for small scale and homemade enterprises as well as cultural events like Last Thursday, discussed in chapter 3. Although Hebdige explores the patterns of style diffusion when a sub-culture gains popularity, he misses an important subcultural possibility. (Hebdige; 1979: 95) I argue that just as Hebdige finds that style becomes adopted by a larger population, ideology can be adopted as well.

However, as grunge was adopted nationally, it became increasingly commercial. At this time, Olympia WA, about two hours from Portland, became host to a new music movement, DIY or riot grrl rock. A third wave feminist music movement, riot grrl rock remained an underground genre, and valued DIY even more explicitly than grunge (Turner, 2001). This music also favored simplistic music over polished practiced rock and amateur over professional. Self-published magazines, or zines, were a common expression of this value and the term DIY became increasingly identified with this movement in particular. (Dominic, 2000)

Largely orchestrated by a community radio, a cassette review self-published magazine, and finally an independent record label called K Records, Olympia became the 
center of this new music subculture. The International Pop Underground festival hosted in Olympia drew thousands, giving evidence that the subculture had gained underground traction. In particular, one Olympia native fueled the development of this subcultureCalvin Johnson. He was a DJ for the radio, lead singer in several main bands, and founder of K records. Support for the subculture came from natives, students at Evergreen College in Olympia, and from people who migrated to Olympia as the scene gained national underground recognition. (Dominic, 2000)

Participation in bands in Olympia resembled the grunge format- members and bands were constantly changing and were typically lo-fidelity recordings made in limited production on cassette and eventually vinyl. Many music festivals were established regionally and many still continue today. K Records is still highly active and based in Olympia. However, while grunge gained commercial and major record label attention, DIY/punk/Riot Grrl music remained underground. (Dominic, 2000)

Jason

To explain what DIY culture is like in practice, I provide the following account of one member of OPS's involvement in DIY culture. Already in the writing stage of my thesis, I decided to check in with OPS and let them know that I was planning to discuss DIY culture. Several members had made reference to its historical subcultural importance during observation, so I asked if anyone in the group wanted to talk with me about the connections they perceived between DIY music and their underground art world. One member responded to my inquiries, explaining that his association with DIY extended to far more than cultural identification. 
Older than the other members of OPS, Jason in particular was highly involved in the punk culture that led to the DIY/riot grrl music, and heart of the DIY/ riot grrl scene in Olympia, WA. While the other members certainly embody, create, and perpetuate DIY culture, Jason helped to found it. For this reason, I feature his story in an extended format to illustrate the way that DIY music formed, and contributed to a wider cultural reality. His involvement illustrates how social resources and cooperative personal involvement in music culture formed the basis of the DIY movement.

Jason's story begins long before the founding of Oregon Painting Society and paints a vivid context for the development of culture in the underground art world in the Pacific Northwest. It illuminates how DIY and punk music influences Jason's approach to art and his long participation in the underground art world. His story shows how involvement in DIY subculture comes through willingness to participate in the underground culture and the ability to network with other likeminded-people. His transition from the music to art world also shows how the two are culturally connected to each other. These cultural patterns are still in practice in OPS's underground art world in Portland.

"My name is Jason Traeger I was born in Seattle WA April 8, 1968. I grew up in Seattle and Tacoma... and at about age 13 I started getting involved in the punk rock scene, started understanding or getting inklings that that existed which was a very, very underground thing at the time. It was incredibly difficult to find information about [punk music] if you lived in a suburban place, or if you lived in a city that...didn't have a scene at the time- like Tacoma (which had one but $i$ didn't know about it, it was very very small)... I went to my first show when I was 13 in Seattle... it just captured my imagination, and it spoke to me at the time [because] it was a unique thing in the culture, ...there was nothing like that for a person like me to get involved in that I thought was as interesting and as self-made and as multifaceted as the punk rock and hard core scene was. The art was really good too, there was a lot of really good bands...and I was at the right age... 
My mom and I moved to San Diego when she married her... high school sweetheart...[in] '84..., I was about... 15. Southern California was kind of a dream for a kid from the Northwest ... there [were] just more bands coming through... The night I got there I saw a show, and I kept going to shows all the time ever since. Being in San Diego it was all about seeing shows in Tijuana, seeing shows in Los Angeles, and going up to the Bay area and making friends with the punk rock scene ... [With my friends in San Diego], we did a fan zine ${ }^{1}$, we put on shows, ...I was really the only one of my circle of friends who was interested in actually playing music, but we were very active in that scene in a very pro-active way.

...In '86 and it all started crumbling and turning just really idiotic and people started getting interested in other things. That was kind of when that punk culture gave way to the indie culture that you know now which is more differentiated [and] more inclusive to women and people who don't necessarily want to hear really aggressive music...[Punk was] just getting dumber and less artistically interesting and less defined. ... It's just a natural thing for a subculture, they run their course. It starts out with innovators and it ends with 3rd generation weird...dogmatic people and copy cats and stylistic imitators... so it just lost my interest somewhat...I had that punk interest and still like that sort of music, but [I] branched out to a lot of other kinds too that had similar energies...

I moved to the Bay area from San Diego, and when I was about 16 I left high school and went on the road with a band called Seven Seconds who were a very popular hardcore band at that time ... Their audience was still very much the punk audience in every city and that was a hugely formative event for me because ... I went to... almost every state in the country... I wasn't in the band but I was the roadie and it was just me and the band.... [We] hung out in New York City, hung out in Washington DC, met all the people from Dischord records ${ }^{2}$, Ian MacKaye and [all the] people who went on to be Fugazi ${ }^{3}$... [who] were still post Minor Threat people.

[These are] people who I know to this day... I ...just hung out with a person last week, Ian Svenonius from the Makeup and Nation of Ulysses ${ }^{4}$, and I first met him when we were both 17 years old, and to be hanging out just randomly because we still know the same people... that's a really strong subculture that had legs...

${ }^{1} \mathrm{~A}$ fan zine is a self-published magazine that is made for and by fans of any given subject. They are typically their distribution is low and they are generally free.

(Wikipedia e., 2011)

${ }^{2}$ Dischord Records is a Washington DC record label that specializes in punk music and early hard core music and is known for its DIY ethic. It is one of the larger independent labels and was founded in 1980. (MacKaye, 2006)

${ }^{3}$ Fugazi is a Washington DC area band that is known for their DIY ethic. They have been on multiple world wide tours, and have seven albums. (Wikipedia f., 2011)

${ }^{4}$ Makeup and Nation of Ulysses are two bands that Ian Svenonius played in from the DC area in the late 1980's. They are a punk rock band and were signed to Dischord records. They are known for their leftist politics, punk fashion, and extreme performances.

(Wikipedia j., 2011) 
That edge then was so Do It Yourself, ... that if you were involved in it in any way that wasn't purely as a spectator, or just a thug ...which there was a lot of those too, then you were involved by either being in a band or making a fanzine, or putting on shows, or putting a band up at your house, or something, and so it was just so participatory... That vibe, I think, in that early phase indicated... [that] there [were] a lot of people who were kind of in it for life and for that ideal of Do It Yourself, make your own scene and your own artistic environment that you want to live in...

[In] the San Francisco era,... I worked for Jello Biafra, who was the singer of the Dead Kennedys $5^{5}$ for a number of years and now he has been a solo artist for the last 30 years or so... I worked for him at Alternative Tentacles $[A T]^{6}$..., I did the mail order for the record label and... I also did all his record trades,... he is a huge record collector, and I got to know him really well and I learned a lot by being there...I just kind of walked right into [that job] because of connections I had, ... my friend ran [the mail order] when I first moved to San Francisco so she was just like, 'work here, we need a new guy', so I started the week I moved there which was kind of amazing.

I worked for Biafra for a number of years, and AT ... then right around '91 I went to the International Pop Underground Convention (IPU) ${ }^{7}$ in Olympia, because I had friends in Olympia... A friend of mine [and I], we were going on a road trip and we were like, 'oh lets plan it around that and we will go and just check out a bunch of bands'. This was just right around that time that [Nirvana's] Nevermind was causing a stir and everybody had advanced cassettes and I worked at AT at the time so I had an advanced cassette long before the album came out and I was like, 'oh yeah this is totally gonna be huge'...

IPU was really an amazing festival and it really was kind of a blueprint for many many festivals to come. This sort of circuit... is a world wide phenomenon- these kinds of indie, small scale, sometimes ideologically driven [festivals],...but there are certainly more in the Northwest than in most places, and they originated here... Ladyfest ${ }^{8}$ originated here, ... What the Heck Fest ${ }^{9}$, Jona from YACHT ${ }^{10}$ used to put on Catch that

${ }^{5}$ Dead Kennedys are a punk rock band who was active in the early 1980's. They produced 5 albums and had a large national and international fan base. (Wikipedia d., 2011)

${ }^{6}$ Alternative Tentacles is an independent punk and spoken word record label that was formed by two members of the Dead Kennedys, Jello Biafra and East Bay Ray.

(Wikipedia a., 2011)

${ }^{7}$ International Pop Underground Convention was a 6 day music festival in Olympia organized by Calvin Johnson in 1991 that featured many well known mostly regional DIY artists. (Wikipedia k., 2011)

${ }^{8}$ Ladyfest is a non-profit music and spoken word festival featuring all female artists that began in 2000 in Olympia. However, it is also hosted in many other cities around the world and is independently organized by each community that hosts it. (Wikipedia 1., 2011)

${ }^{9}$ Heckfest, or What the Heck fest is a music, film, literature, and art festival in Anacortes, WA that began in 2001 and is a community based event. (Wikipedia i., 2011) 
Beat $^{11}$ down in Astoria every year, ...Helsing junction ${ }^{12}$... Calvin has done-this is the seventh year, this last Heck fest was like the eighth or something... Those are really culture building things, and ... IPU was kind of the blueprint. I got there for that.

I liked the scene, I liked what was happening, and at that time I was really interested in moving back up to the Northwest, because I was from here and I always wanted to move back when I lived in California... I had visited Seattle, I had visited Bellingham and some other cities, but... as soon as $i$ went to IPU I was like, 'Olympia is the place to be 'cause its small, cheap, but very active, seems like if you just make it happen there you can really make something happen'...Strangely enough, I was put in touch with Calvin Johnson ${ }^{13}$ who I had only met once before through Fugazi...Calvin had just bought his house that he lives in today, and he needed a roommate.... Ian MacKay had introduced the two of us and ...he told Calvin, 'yeah Jason will work out with you, you guys would get along well', so on that recommendation [Calvin] was like, 'OK it'll be awesome' so he had [me and my girlfriend] move in... We lived together for like two years maybe until my girlfriend and I moved out to get our own place...

Then I worked at K [Records] $]^{14}$ after that... for ... 5 or 6 years and was deeply immersed in the whole riot grrl thing. I was good friends with...the people that became Sleater Kinney ${ }^{15}$, Corin and Carrie, and their band, Heavens to Betsy ${ }^{16}$. [I] was friends with Bikini Kill ${ }^{17}$ and those people... Olympia is very small town and even if you are not close with somebody, everybody just is in your orbit and you know everybody...

I got really into performing myself as a solo artist... I put out a record on $K$ and on a record label called Atlas and on a bunch of compilations and I was kind of doing a spiritual troubadour thing... So I toured the country a number of times. Olympia was... about hunkering down and just trying to get creative and actually do something with

${ }^{10} \mathrm{YACHT}$ is a current Portland area band that has produced 5 albums. (Wikipedia n., 2011)

${ }^{11}$ Catch that beat is a music festival that is hosted in Astoria Oregon and features bands from the Pacific Northwest. (Strickland, 2006)

${ }^{12}$ Helsing Junction is an annual music festival hosted by K Records at an organic farm in Rochester, WA. (Helsing Junction Farm, 2011)

${ }^{13}$ Calvin Johnson is an important figure in the independent music scene who was born and currently resides in Olympia. He is in several indie bands such as Beat Happening and the Halo Benders, and founded the record label K Records. He organizes music festivals as well. (Wikipedia c., 2011)

${ }^{14} \mathrm{~K}$ Records is an independent record label founded in 1982 by Calvin Johnson that prides itself on its anti-corporate sentiments and DIY ethic. (K Records, 2011)

${ }^{15}$ Sleater Kinney was a Portland area riot grrl indie band that was formed in Olympia, and is known for its feminist and liberal politics. (Wikipedia m., 2011)

${ }^{16}$ Heavens to Betsy is an early 1990 's riot grrl feminist band from Olympia signed to K Records. (Wikipedia h., 2011)

${ }^{17}$ Bikini Kill is an Olympia based punk band founded in 1990 often credited with founding the riot grrl musical style and are known for their feminist lyrics. (Wikipedia b, 2011) 
music rather than just working in it and with performance and just exploring my own personality through music and art....

I think...part of what makes the place so special is [that] there [are] basically three feeds to Olympia-...the locals, which is undeniable and kind of amazing how many good musicians... and cool bands emerged from ... people who grew up there ... Calvin being the archetype of it, and then you have the Evergreen [College $]^{18}$ people ...Evergreen being the school it is, it brings people in with free spirits, who are creative and interesting ... so it constantly gets reseeded with new generations of people who stay and continue to have venues and promote shows and create alternative culture in a place that could very well not have anything ... and then the other ones are people like... me who... just [want to] live there ...

Towards the end of my Olympia thing I kind of lost interest in doing music performance, and had always done visual art ..., I had done a lot in punk and done a lot of fliers in the old days and things but, I turned towards comedy and I started doing standup comedy in Seattle and open mics quite often ... and moved to Los Angeles, [and decided] ...comedy just...isn't my thing to do... [Instead] I was...driven towards... really focus[ing] on making art, under the umbrella of art being all the things I want to do, ... painting, comedy, music, experimental stuff, ... whatever,... So that's the path that I have chased ever since, basically... the seven years that I have been in Portland, which brings us up to today with my work with Oregon Painting Society, and as a visual artist,... exhibiting installations and oil paintings still ensconced in the current underground scene of Portland. ... [I chose Portland] because I wanted to be back in the Northwest but I didn't want to live in Seattle, and I wanted to go to school to study art ... I dropped out of high school and I never was in a classroom again until I was in my 30's, and so ... I looked at PNCA [Pacific Northwest College of Art] and I liked what it had to offer ... So I went to school and I really am glad a made the choice...I also have long time family ties in this area...

[I think the underground stays active in the Pacific Northwest] because [music] runs deep in the culture and the bands run deep in the culture...or musicians, not necessary the same band, but like musical entities and people... Especially amongst people who aren't religious... music scenes like that can create families that stick together... I was thinking about that at Helsing Junction last weekend, I have friends here that I met like two months ago in Portland and I have friends that I met in 1990 in Olympia, and I know people who's kids I held as a newborn and now they are like back from college, ... and they were still coming back to the same place because it's an enduring enough thing.. That and the precipitation and weather, I think have a lot to do with it... You have to be indoors for so much of the year, you can get into your projects and go a little deeper with the bands, and get a little more under the surface of things, and the houses have basements...Portland is so nice, its inexpensive and you got a lot of space compared to most cities that have interesting things going on. In that way Portland [is like] a big Olympia,... it is a place that has just got a lot of energy.

${ }^{18}$ Evergreen State College is a non-traditional liberal arts university in Olympia that issues no grades, but evaluations, and has produced many notable musicians and artists. It is acclaimed for its high quality of instruction. (Evergreen State College, 2011) 
People sometimes deride [DIY]...[and say] it's...pretentious...crafty, or the people... are privileged... [But] it's [the same as] ... eating well, knowing how to cook and can..., and the interest in stuff like where your food comes from... These are skills that are good for people to learn and whoever is learning them in the culture is doing a favor to the culture ... Its the same thing with DIY, ... anytime you learn how to do anything for yourself you are a more empowered person and you can just spread that and share it and put it into practice somewhere else... DIY is really about curiosity, ultimately, curiosity about people and curiosity about your own potential. ... What can i do on my own? What can $i$ do outside of an institution?... Or outside of culturally acceptable terms? What do I want to say with my heart? And what do I want to say with my culture and my music and what does it stand for? And to see... your views [align] with people, it shows me that ...

these are lasting relationships with really quality people... Whatever faults I can find with the subcultures or things that are silly about them, it's been a good crew that has hauled in a lot of really amazing people and I'm honored to know all the different people I have. [I have] learned so much from all of them including the young people I work with today doing projects that are amazing, ...[and] that's rad."

\section{Portland's Art World}

It is important to understand the dynamics of the art scene in the city. Portland's art world exists in two major areas, the Northwest and the Northeast. These two areas illustrate the differences between the established and the underground art world.

The established art world is based in Northwest Portland, especially the Pearl District. A trendy area just north of downtown, the Pearl features street car access, green living in high rise lofts, boutiques, high end shopping, and art. This art world is driven by established elite channels of support. The Pearl gained its reputation through the efforts of a few galleries, many funded by wealthy families, beginning in the 1970's (Foster, 2008). The area was reclaimed from empty industrial warehouses and crime, and these warehouses have become anything from design firms, to event spaces, and five star restaurants. The current economic recession has driven many newer galleries in the area out of business, and even the most well-established galleries have suffered financial loss in the wake of lower sales. (Row, 2010) However, the Pearl still thrives, and is known 
for its well established galleries and hosts an art walk on the first Thursday of each month.

The major attraction for First Thursdays are galleries hosting openings of new shows, and lasts from 6-9pm. This art walk produces a large turnout, anywhere from 500 to 800 (Portland Art Dealers Association, 2011), and follows a similar format to other art walks, gallery goers peruse the streets and enjoy light drinks and snacks at galleries. The art featured here is carefully chosen, professionally critiqued work. This art walk was founded 25 years ago, and is organized and sponsored by the Portland Art Dealers Association. First Thursday is celebrated for its arts culture and its economic stimulus (Portland Art Dealers Association, 2011)

Conversely, the underground art world is based in Northeast Portland, especially the Alberta Arts district. Located across the river from downtown, the Northeast is a mainly residential, historically low income area although it has becoming increasingly gentrified as its reputation for the arts has developed. However, many cheap rental housing options are still available, most in the form of large houses that many people rent together. This area is known for its indie flare, and is home to boutiques, galleries, cafes, record stores, and local music along its two major streets, Alberta and Mississippi. Galleries in the Northeast are known for less traditional, more outsider art.

This neighborhood also hosts an art walk, but with a very different flavor and format than its Northeast counterpart. This event is hosted on the Last Thursday of each month, and the major attraction is the street itself. Although it began thirteen years ago by 
the efforts of three Alberta galleries, and they served only as a catalyst for the event as it exists today.

Rather than a traditional gallery hop with wines and cheeses, NE Alberta Street is home to a vibrant, decentralized street festival. This street fair does not take dues nor is it organized by any entity, artists set up booths in the streets which are shut down by large crowds without formal permission from the city, and generally over 10,000 people turn out to peruse a truly DIY event. In contrast to First Thursday's organizers, the closest organizing body that Last Thursday has is Friends of Last Thursday, a non-profit that offers technical rules and updates on its website, details about what to expect as a vendor, and organizes a small number of volunteers for cleanup (Friends of Last Thursday, 2011). However, they serve no concrete organizing function and hold no authority on what happens there. Although it is framed as an art walk since Alberta galleries also host their openings during the events, the attraction is generally the flame-throwers, painters, circuses, jewelry makers, break dancers, etc. that set up along the one mile stretch. The significance of this event is that Portlanders demonstrate cultural enthusiasm for DIY art. Last Thursday goers are not drawn by the professional critic's endorsement of a particular show, but rather by the cultural beat of the street festival. While this is sparked controversy about the noise, crowd, and general disruptiveness of the event, it is recognized as an identity creator and organizes around DIY artists (Row, 2010).

\section{Gentrification and Alberta Arts}

An analysis of the Alberta Arts District would be incomplete without a discussion of the impacts of gentrification in the neighborhood. While the arts culture may be on the rise, the low income population that lived there before is increasingly displaced by rising 
rent and property values. In regards to Last Thursday, there is a divide between long-term residents, new homeowners, and renting artists about whether the event represents positive or negative change in the neighborhood. For long-term residents, the event represents a culture that they are not a part of. However, newer homeowners welcome the event, many having moved into the area for the artistic flavor of the neighborhood. Artists themselves feel mixed. They like the cultural force of the event, but since many of the artists at the event are not from the neighborhood and because much of the art displayed there is somewhat amateur they do not quite endorse it. (Shaw and Sullivan, 2011)

Regardless of the event however, the role of artists in gentrification is undeniable. However gentrification displaces artists as well as long term residents. Lloyd finds that while artists certainly create the reputation and conditions for gentrification, they live in low income places because they too are a low income population. Artists expressed negative sentiments about gentrification, and often cited that in addition to the cheap rent, low income areas carried cultural bohemian appeal that is passed down through a long history of artists living in poverty for the greater good of their work. Thus, while not an irrelevant negative effect of artists in the area, they too are victim to the effects of rising costs of living. (Lloyd, 2004) Importantly though, artists often choose to live in poverty since many hold degrees and if not for their art would likely have more lucrative career choices while original residents do not have these elite possibilities. For them, poverty is a decision rather than a pre-condition for their careers. As passive and often unwilling participants in gentrification, artists' role in neighborhood development is worthy of 
further inquiry as a lens for understanding how the process of gentrification happens.

However, this is beyond the scope of this research as this research.

\section{Case Selection, Oregon Painting Society}

Oregon Painting Society members are part of this underground neighborhood art world. With the exception of one who lives nearby, OPS members live in one large house in the Northeast located very close to Mississippi, which is similar to Alberta Street in features and reputation, and only about two miles away. Members of OPS are within walking distance to virtually the entire Northeast art world.

OPS is a good example of what artists living in the Alberta Arts district are like. Although they met through art school affiliations, OPS members all share some involvement in the DIY music scene before their group officially formed. Their group history, introduced here and discussed at more length in methods, illustrates the values of the underground art world, specifically the DIY ethic that drives production in this world.

The number of projects each member of OPS has been involved in speaks to the emerging nature of the scene, as well as the cultural inclination to choose artistic freedom and creativity over long-term reputation. Four members of OPS have toured nationally with their bands, some with multiple bands. Their involvement in the art world is not solely limited to OPS projects. Each member pursues individual artistic and musical ventures in addition to their work with their group. Their artistic and musical pursuits illustrate that while grunge helped to draw attention to the Pacific Northwest and create a reputation for Portland that attracts like-minded people, the DIY scene was influential to artists living here already, and created the framework for the way that the underground scene functions. 


\section{How OPS formed}

Although many artists throughout art history choose to work together, the composition of an artist collective is not uniform. In this case, Jason was the first person to conceptualize forming an artist collective and decided on the name Oregon Painting Society before the group had formed, and without any intention of necessarily involving painting in the activities of the group. He also had no concept of who would be in the group outside of the notion that he loved working with other people, and was friends with artists that he thought where incredible. The first OPS show was only a two person collective, Jason and a friend Lliam. After that show, the group gained more traction and began scheduling more shows. Several people were involved in the collective but there was no set number of people or official members for the first few shows. Jason's girlfriend, for example, was a big part of OPS at the beginning, but eventually had to retire her involvement to focus more on her design career. The current members all became involved in early shows, Jason started working with Birch by the second show, who he met through Barb. Birch brought musical and sculptural influence to the group. Brenna began working with the group as well and was present in the brainstorming stages of the collective by happy consequence, as she was living with Barb and Birch already. Brenna recruited Matt after he returned from an overseas tour with a band he was playing with, Parenthetical Girls. Matt, mostly a musical artist, decided to join because visual collaboration seemed new and interesting. Jason knew Barb from art school, and although she was a major catalyst for the group forming, she became more involved with the group after she graduated and had time to work on projects outside of her thesis. Other members 
eventually drifted away to work on other projects, and the five current members crystallized their group. Their work has ranged from interactive musical sculpture, to film, to performance, to sculptural installations, and everything in between.

\section{Conclusion}

This cultural context explains the ideology that forms the underground art scene that supports many artists in Portland and sets the stage for examining Portland's scene as part of a regional identity. In this chapter, I have established that Portland's underground art scene is a byproduct of the cultural value of DIY shared by Portlanders and the surrounding region. Grunge established DIY as regionally specific to a national audience, while DIY was embraced by local artists as they formed the underground art and music scene in the area. Portland's art world shows this DIY presence in the divide between the established and underground art world in the way that they attract audiences and celebrate the art each neighborhood features. Jason's story shows that participation in the DIY world comes from social connections and personal involvement in the music and art scene. OPS has strong roots in the DIY culture and is deeply integrated into the underground art world in the Northeast. OPS' story of forming shows the DIY ethic, they formed because they wanted to make art, and they chose to do so with friends and pursue their work as part of their multi-faceted involvement in the art scene. 


\section{Chapter 3: LITERATURE REVIEW AND THEORY}

\section{Introduction}

This chapter provides a framework for understanding how art work is done using Becker's analysis of art worlds. Becker explains artistic production by exploring the elements of human coordination that must be present for art to be created, shown, and sold. This conceptualization is helpful for this project as it explains how artists do their work from a social perspective, and also as it describes the way that the social system of art influences what can be made and sold. The concept of art worlds addresses my first two research questions,

\section{How do collectives help artists to sustain their artistic practice?}

\section{How is Portland's underground art world structured and sustained?}

However, while he provides an excellent lens for tracing the factors contributing to the production of art by placing the pooling and flow of resources at the heart of an Art World, his framework is incomplete. By using a top-down strategy for defining the boundaries of an art world, and by only considering monetary resource flows, he fails to articulate a complete picture of the art world social system. Also, the work has been dated by historical, economic, and subcultural changes since it 1982 publication. Another missing element in Becker's analysis of Art Worlds is the variable of place. Some cities rank higher for art than others, different cities are known for different kinds of art. Thus, Becker misses the importance of cultural influence and macro-economic influence that location has on art worlds.

In order to answer my third question,

3. How is the underground art world sustained by place? 
I look to Richard Florida's work on the creative class to discuss how the implications of place in light of the migratory and cultural shifts in creative workers contribute Portlander's support for the underground art world. Jim Shorthose's and Gerard Strange's concept of creative ecologies helps to focus Florida's work on fine artists. It provides a framework for interpreting what the implications of this cultural shift are for artists on a daily basis by translating cultural values into neighborhood resources and networks provided by clustered creative people. Wallerstien's World System Perspective adds regional specificity to the theory by considering art worlds as part of a larger economic system that funds the making of art. Finally, I consider Portland's sub-cultural values in the wake of punk, DIY, and internet availability to explore the decentralized nature of the Portland art world.

\section{Resources are the Building Blocks of Art Worlds}

Becker conceptualizes Art Worlds around the production of art as a system, or world, based in the flow of resources. This theory provides an excellent lens for understanding how art systems are perpetuated and how art movements flow through the intuitions of an art world.

It Takes a Village to Make a Painting

Becker's analysis in Art Worlds focuses on the organizational system surrounding the production of art rather than the subject matter of individual art works in isolation from their social context (Becker, 1982:1). This is an important distinction because it acknowledges that art works do not stand alone. They are part of a larger social sphereBecker calls this an art world (Becker, 1982:1). These worlds are constructed by 
cooperative links, or ways to coordinate the production and consumption of art. From inception to eventual sale, many people must participate in the process of artistic creation, thus cooperative links make the system of an art world. Over time, art worlds are born and die depending on the presence of cooperative links between agents involved in the production of art. For instance, workers must dry and stretch a canvas, art supply stores must sell it, an artist must buy and paint on it, gallery owners hang it on their walls, and individuals buy it. If any of these links are broken, the world becomes unstable. If painters no longer want the kind of paint available to them, a new cooperative link must be forged. (Becker, 1982:2-6)

\section{He Who Has the Resources Makes the Rules}

Cooperative links are at the heart of the organization of an art world because they create a social capacity for the flow of resources between actors in that world (Becker, 1982:25). Just as agriculture aids communities in stocking food resources faster than an individual could by hunting and gathering, an art world concentrates resources necessary to for individuals to continue the production of art and for the reproduction of the art world.

These cooperative links generate the principles that guide the way the art world operates because they create a consensus on what qualifies as art, and who qualifies as an artist as they place structural limitations on the kind of art that can be made and consumed. That is, worlds develop in particular ways depending on the needs and values of the people who comprise them in every step of the process. The needs of a painter are not the same as the needs of an actor. Similarly, the needs of a gallery owner are not the same as the needs of a theater venue. (Becker, 1982:35) 


\section{Changes in Resources means Change in Art Worlds}

Becker's concept of cooperative links is also useful because it provides a way to judge whether or not a change or revolution has occurred in an art world. Since Becker judges change in an art world by discontinuation of these links, an evaluation of the links provides insight about where worlds overlap and where they separate.

In the event that a new art world has created alternative cooperative links in place of the old art world's links, a revolution has taken place. These revolutions fuel increased artistic freedom and a reframing of what art is and who artists are. Artists create the boundaries of new worlds as they create the art that the world becomes centered around. Resource coordination must become crystallized around a common project, and artists decide the scope of the project. That is, since the process of an art world is dependent on the kind of art that is made, artists who found the art world provide the focus for resource organization because they make the art. However freedoms are not absolute, but are based on available resources. If there are no available cooperative links or no way to forge them, the world must submit some of its organization to existing structures- such as the market that is available to purchase art. Conversely, after crystallization, art worlds limit artistic freedom because the new freedoms that existed at the inception of the world become boundaries that make up their cooperative links. (Becker, 1982:305-306) Becker's Commercial Gallery System

Becker provides an in-depth description of the commercial gallery system as a series of cooperative links that revolve around competitive resources. This system operates by creating a flow of money and credentials from one group of people to the next. He explains the commercial art world as an economic system based on six major 


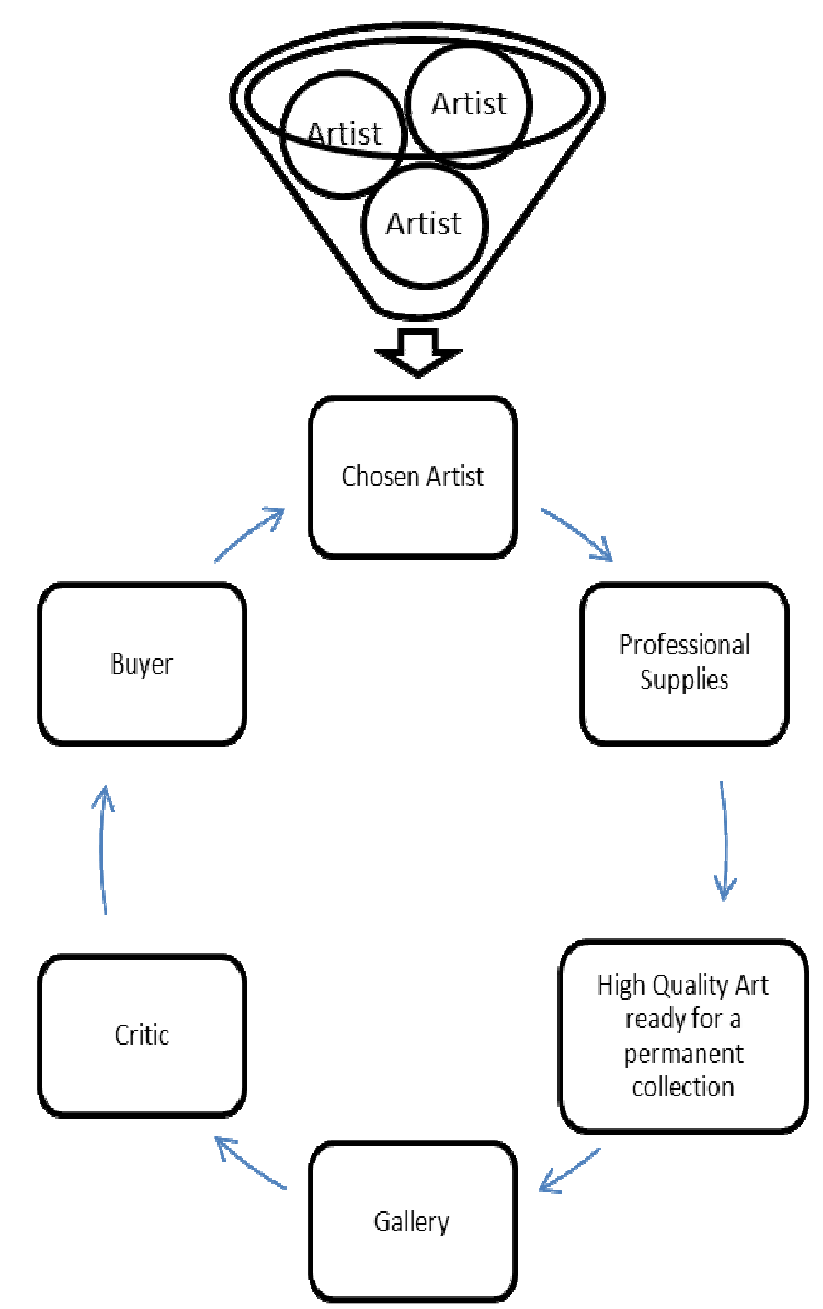

Figure 1 The Commercial Gallery System

components, (see figure 1). From a large pool of candidates, individual artists are chosen by a gallery for a show. These are artists who have met, in the opinion of the gallery, professional standards. Professional standards in this art world are determined by the work's ability to attract buyers. High quality art supplies and expert construction appropriate for a long-term private collection and renown of the artist are important in this process because they give monetary value to the work. Galleries must make decisions on featured artists carefully because their reputation is built on art critics' judgment of the 
quality of the art work shown there. An art critic assigns credentials to the work my mention in official published channels, such as art magazines or newspapers. If the show receives favorable reviews, the gallery and the artist are likely to attract the attention of collectors. This reputation is reinforced by a population of gallery browsers. Although they do not contribute any material resources to the art world, they are a link between professional critique and cultural validation of the gallery. These elements are a system for assigning value to artwork. Ultimately, elite buyers purchase the artwork for large amounts of money, providing the final validation for the work. The money then trickles down through the other links. Galleries take a percentage of the sale, and artists receive what is left. They use the money to perpetuate the making of artwork. The money buys professional grade supplies, and the process of making art to be represented in galleries starts over. Critics who validate successful shows are given higher ranking in the world of art credentialing, and both popular and elite audiences pay greater attention to their valuation of art. (Becker, 1982:110-112)

The commercial gallery system is organized around institutionalized credentialing processes that establish reputations and assign value. This model stresses the attention of elite art critics and patrons, who grant credentials and access to the market to individual artists (Becker, 1982:111). In this world, every link carries professional reputations steeped in monopolistic projections about what constitutes good art. Reputations come from the top down, from those who are part of the cultural elite. (Becker, 1982:115) This creates a highly competitive way of allocating resources, those whose reputations rank high are richly rewarded while others join the ranks of starving artists (Becker, 1982: 109). That these particular cooperative links create competition is especially critical. The 
structure of the commercial gallery world not only facilitates resource flow, but it creates a competitive ideology based on the monetary value of artwork. Thus, the aim of this system is primarily to sell art (Becker, 1982:113). This Art for Sale ideology is the root of the difference between creative ecologies described by Shorthose and Strange and the established world of fine art.

\section{Limitations of the Framework}

In Becker's conceptualization, a fine art world's cooperative links always forge competitive economic relationships. This perspective most likely due to the scope of his focus- which was the commercial art system in 1982. Although Art Worlds is not based on a particular study, Becker continuously illustrates his theory with art worlds that are well integrated into a traditional art world economy. From ballet to jazz musicians, to painters, these are all forms of art that are salable and desirable to the traditional elite buyer, or in other words they are professionalized outputs of art. Thus, all of the cooperative links that he describes have similar competitive economic components.

This similarity means that revolutions for Becker are a change in style rather than structure (Becker, 1982:307). The economic logic of the world remains the same, but the actors who compose the intuitions change. While these changes are still noteworthy (art history is built around them!), the framework cannot account for all of the kinds of changes art worlds might go through. For example, a shift in economic logic changes the way that the world operates rather than just changing the aesthetic tastes of the institutions because of the change in the way resources flow.

Thus, Becker's framework is not wrong but only provides a static explanation for the important elements of change in the elite fine art world because he does not account 
for system changes that occur with changing values surrounding artistic production. He also lacks a consideration for possibility of more than one kind of fine art world, as his revolutions always take the place of the old system. Becker does not conceptualize diversification of an Art World that might come with artists pooling resources without channeling the structure of the established art world system. Essentially, the fallacy is that this theory assumes only one professionalized platform for showing art rather than considering the possibility of multiple kinds of systems at work in the same art world. By assuming that the project of the art world is centralized, Becker misses the diversity of systems that art worlds can encompass.

Because Becker traces the art world from the top down, beginning with professionalized art outlets, rather than by tracing the system through the way that artists navigate their work sphere, he misses important components of that world. Specifically, he misses the underground art world that is both a work setting and a cultural dimension of artists. This world distributes more resources, including both social and artistic resources, to more artists, than the professional monetary world does. Since the professional art world acts as a highly competitive funnel for just a few chosen artists, there is an alternative system that encompasses a much larger and complete population of artists. Thus, while his description of the commercial gallery system is valid, it is only representative of a small sphere of a more diverse world of art. By placing artists at the center of analysis rather than a gallery it is possible to map a more complete picture of the entire Art World.

Additionally, the art world that Becker describes is dated. Historical, economic, and subcultural changes that have occurred since the book was written in 1982 challenge 
his theory. These changes have shifted the role of the institutions that Becker describes especially since art movements with particular style have subsided. This makes his analysis of art world revolutions inapplicable and too stringently categorized for the reality of changes that happen in art worlds now. That is, because he only considers revolution in art worlds as stylistic movements that replace existing intuitions with new actors using the same kind of system, he misses the other dimensions of art world change that are encompassed by the proliferation of artist collectives and the cooperative values they bring with them.

Decentralization of established power is a major component of art world change since 1982 and has occurred with the technological revolution, particularly with the ability for artists to represent themselves on the Internet. Personal web pages and social networking sites give artists the ability to reach audiences directly, rather than relying on publicity from galleries, magazines, or newspapers. The need for representation and review in order to gain support for artwork is now augmented by personal agency.

Also, Becker generalizes the art system without considering the cultural differences in art worlds from a regional perspective. That is, because art worlds are integrated into the larger social system of cities, it is important to account for differences in the way each art system functions based on regional culture. In Portland's case, the cultural ideology of the people interested and participating in the arts is linked to its organization. The DIY (or Do It Yourself) ethic generated by the grunge/punk subculture in the 1990's in the Pacific Northwest has diffused into Portland's local culture and makes the art system work on a much more decentralized model than what Becker describes. This ethic provides support for fledgling artists, as people are inclined to seek 
less established outlets for finding art, such as edgier events like Last Thursday which requires no monetary commitment from its participants. This less established outlet for accessing art also reduces the weight of professional critique since the appeal of the event is based not on established professional reputation, but on the opposite- lighthearted, disorganized creative chaos. This DIY ethic diffuses the importance of the professional sphere of art for both artists and audience, placing greater emphasis on the generation of culture than the sale of art itself.

\section{The Importance of Place: Specificity in Art worlds}

\section{Creative Environments Enhance Artistic Development}

Shorthose and Strange offer a different perspective of an art world called creative ecologies. Instead of focusing solely on its economic components like Becker, they describe artistic production systems involving both culture and work. (Shorthose and Strange, 2004). They answer the question of how artists in collectives sustain their artistic production by tying social support and connection to community to production. At the core is the value system of the underground art world that shapes what the art world looks like. They point out that "artistic labour often occurs within communities of similarly independent artists, working within radically new, relatively self-determined informal networks and mutual support systems (Shorthose and Strange, 2004: 48).” These ecologies are characterized by mutual goals, fluid relationships, and continuous creative feedback. Unlike Becker's art worlds, the system is comprised primarily of artists (Shorthose and Strange, 2004:47).

Relationships between artists in their view are social, characterized by sharing and a high reliance on one's own and others' skills. Through dense social relations artists 
break the boundaries that characterize the established art world economy. In contrast to single gallery representation, artists participating in creative ecologies have multiple projects with multiple people and base their production in available resources, not expensive art supplies. They have high levels of collaboration and cooperation with more peers and couple work and social relationships, unlike the established art world. Participants in creative ecologies affirm the concept of art for art sake, and in doing so, develop a cultural resistance to commercialization. (Shorthose and Strange, 2004:54) Additionally, participation in a creative ecology community is voluntary and localized. Artists who live and work in creative ecologies are making a conscious effort to be in community with one another, and the pathways to this cooperation are determined by place since the kinds of exchange that take place usually must be transacted in person, as when artists give inspiration, time, or skill to each other. (Shorthose and Strange, 2004:49) Sharing skills allows artists to sharply lower the cost of making art. For example, if your neighbor shares her circular saw, you no longer need to buy one for the construction of your project. A creative ecology is localized, and grows from existing culture guided by its participants and the skills and resources they have (Shorthose and Strange, 2004: 49).

The concept of creative ecologies is important because it begins to capture the relationship of artists to their social environment as part of the work they do. However, Shorthose and Strange focus on policy implications of these creative environments (Shorthose and Strange, 2004:53). They miss the lived reality of artists and provide no account of how these values play out in micro settings. This is unfortunate because Shorthose's policy suggestions in his discussion of creative ecologies and also on creative 
neighborhood building (Shorthose, 2004) are based on the claim that supporting DIY cultural processes at work in creative ecologies is a more appropriate way of encouraging creative production than pouring funding into the established art world. My research seeks to expand an understanding of creative ecologies by adding an ethnographic account of how artists embedded in these cultural systems live.

Shorthose and Strange's work must also be reframed for a second reason, they study creative ecologies in the UK. It is likely that significant differences exist between the UK and the US in the relationship artists have to the economy since cultural and governmental support for the arts varies. My research gives a close look at the reality of artists in Portland as an example of a local creative ecology culture. Migratory Patterns Show Concentrations of Creativity

The work of Becker and Shorthose and Strange framed my first two research questions. Richard Florida's The Rise of the Creative Class begins to frame my third question, How is the underground art world sustained by place? Florida explains how cities can attract economic growth based on the amenities they offer to creative people. Focusing on the "creative class" Florida calls attention to the way that the migration patterns in the US of creative people, change local art worlds. In contrast to work on class in terms of only income, Florida conceptualizes class in terms of the kind of work that a person does and how that kind of work shapes their value systems (Florida, 2002:68). Members of the creative class include,

"people in science, engineering, architecture and design, education, arts, music, and entertainment, whose economic function is to create new ideas, new technology, and/or new creative content.... [and] also includes a broader group of creative professionals in business and finance, law, health care... These people engage in complex problem solving that involved a great deal of 
independent judgment and requires high levels of education or human capital." (Florida, 2002:8)

Through comparative quantitative analysis of US cities' migratory trends, he finds that creative people are choosing where to live based more on city reputations and lifestyle amenities than they do on job availability or family ties (Florida, 2002: 166-168, 232). Florida's analysis helps understand how the values of DIY culture in Portland attracted a concentration of creative people living in the city for the purpose of accessing creative amenities that support an alternative art scene. Jason's story in chapter 2 is an example of someone who came to Portland to do creative work.

Portland is an exemplary creative class city. Although joblessness is higher in Portland than many other cities, Portland is still a magnet for a large influx of young creative people. Portland offers livability to newcomers, it is medium sized, has strong neighborhood structure, good public transit options, natural beauty, and culture. The influx supports monthly events such as the Last Thursday Art Walk which is an unofficial street festival that draws thousands every month. The focus on doing and viewing art supports the ethic of self-representation and cultural creation, or Do It Yourself (DIY).

However, while Florida explains why artists and others of the creative class move to Portland, he does not consider how Portland's DIY artists support their work and sustain their lives. Florida argues that the key to stimulating urban economic growth is to provide flexible, challenging, creative jobs (Florida, 2002:268), this is hardly relevant to DIY artists.

What Florida misses is the distinction between fine artists and other creative class workers. He defines the category of creative class too broadly. For example, he includes 
doctors who while independent and self-driven, are part of an established system medical system of hospital privileges and referrals. However, fine artists are permanent free agents until they are represented by a gallery. This representation often only comes later in life, or for most fine artists, never. Because the commercial gallery system is designed to be exclusive and the majority of fine artists are not supported by it, their work experience is qualitatively different than the stable work world that Florida anticipates. Instead, Florida's concept applies to other art professions, like design. Although some designers are free agents, it is normal for them to work for design firms that have regular clients, and pay salaries, or at least hourly wages. In contrast, even gallery represented fine artists cannot enjoy the privilege of a regular income because their work is based on sale of individual works.

Because the nature of art work is different, artists have different needs for city amenities. Artists who struggle to make a living need cheap housing and food stamps. Because Florida's model does not focus on fine art, but rather other creative workers, his conclusions are not relevant to fine artists. He is able to explain what values and amenities draw the creative class, but it does not account for the ways that some cities enable the concentrations of creatives that make an underground world of art.

It is also likely that Florida misrepresents the number of artists living in a city because he uses occupational classifications determined by income from U.S. Bureau of Labor Statistics. Essentially his data is flawed in the same way that Becker's theory of the Art World is- it assumes that artistic activity can be measured by counting those who make a living from art. Many artists must work other jobs, not necessarily creative ones, to support their main work- the production of art. For many artists their career work as an 
artist is detached from work for their income. Although highly educated, more than a third of artists in a Chicago survey reported an income lower than 25,000 a year and seventy-three percent did not make half of their income on art (Lloyd, 2011). Thus, there is no way to know if the trends that Florida suggests for fine artists are actually representative of the population. This is a methodological problem since the population of artists who are not making a living from their work is not easily accessible for large scale analysis. In place of a quantitative study, this project seeks to fill that gap by providing an in-depth qualitative understanding of how Portland underground artists are supported by their city.

Economy and Geography affect Art Worlds

To answer my third research question, I asked What characteristics about Portland contribute to its underground art world?. Art worlds in cities do not exist in isolation from each other but are part of a larger scheme of national and even international production and influence. Cities with well-known reputations for the arts, such as New York or Los Angeles, make up the core cities of fine art culture in the US and they have the most competitive art systems since they attract a large number of artists and funding for contemporary work. They have wealthier populations, and thus can provide higher reward for artistic success. Such places build on sub-cultural legacies, such as Andy Warhol's Factory. Artists move to them with high hopes of becoming the next art star. These cities require a lot from their artists. Because the reputation of the city is so developed, the creative ecology of that art world is much less accessible and flexible. That is, artists may still be concentrated into creative neighborhoods, like Brooklyn, but the cheap housing that once attracted them is replaced by expensive trendy 
lofts. The artists that live there must meet a high financial threshold to live, never mind do their work, and so a high reliance on the established art world is necessary because it provides high monetary rewards to the artists who can access it. Also, core art cities are also subject to economic change. When the economy is good, the core cities have a wealth of funding to provide to the art world. This money comes from grants and individual sales. In times of recession, this flow wanes as money must be directed towards more essential purchases.

Other, less established art cities are still destinations for young artists and have healthy creative ecologies in the absence of supportive funding. These cities offer cheap housing in addition to good, although not extremely well known, reputations for the arts. They are places where the general creative class is concentrating and where the values of the creative class are being diffused on some level. Living as an artist in these cities is cheaper than living in a core city and the concentration of artists is still high. The core cities often look to these semi-periphery cities for new artists featured in their established systems and so semi-peripheral cities also offer increased visibility to artists who live there (Lloyd, 2004). These cities have some kind of established commercial art world a la Becker but they also have built in flexibility created by lower costs of living that come with a less developed city-wide reputation for the arts. Importantly, these art worlds do not have the monetary flow of core cities, but rather their resource base comes from low overhead cost and alternative DIY culture.

Finally, the most peripheral art cities are those that might attempt to promote the arts but have a deficit in cultural history and city amenities to sustain a successful fine art world, like Columbus, $\mathrm{OH}$. In these cities, there is some population of creative people 
and cheap housing to sustain them, but the lack of cultural and financial interest in the arts fails to keep them in these cities. Importantly though, these cities often concentrate young artists from rural places in the surrounding region and serve an important function, often facilitating initial concentration of artists as they attend art schools and learn about where more people in their subculture live.

These cities are also interconnected. Commercial systems at each level of the fine art subculture replicate and orient themselves toward the core cities' established competitive system. Each established fine art system is based in competitive monetary relationships regardless of its sub-cultural relationship to the core. Thus, none of the established organizational structures for showing art support the majority of artists who are trying to access it. Also, this means that even the artists who are supported by the established system outside of core cities are likely still oriented towards a higher margin of success that would be granted by the core cities. One of the main ways that core cities attract new artists is by geographic proximity. Artists in semi-periphery cities close by are often recruited from the existing pool of artists to join the core cities' artists who are supported by the established system.

Blazak (1991) connects artistic core cities, or bohemias, and global economic flux and flow. He shows that when the economy is experiencing an upswing, the cultural production in creative centers rises. This is because there is money that flows to these creative endeavors through grants and sales of work. The larger the flow of money, the more artists there are that can be supported by the system. (Blazak, 1991:116) However, because his work focuses on core creative cities, he fails to capture the full perspective suggested here. 
In the case of recession, semi-peripheral art cities hold some immunity for artists. That is, because the flow of monetary support for the arts is smaller and less consistent than the flow in core cities, changes in the flow of monetary resources matter less. Additionally, during recession, participation in an underground art world also offers benefits. Even without much funding for the arts, Portland's established art world suffers during recession. Many galleries who are paying high rent for prime location must close, and artists who show work to be sold at high prices are able to sell less (Row, 2011). However, this deficit is less apparent in systems that largely rely on non-monetary resources to produce and show work.

This isolation is important in explaining Portland's scene, which is demonstrating a healthy creative culture during economic recession. Portland occupies a semi-peripheral place in the sphere of fine art on a national level. It has a semi-underground reputation for the arts, and is host to an influx of young creatives. In fact, although Oregon's migration rates have slowed in the recession as unemployment increases (Jurjevich, 2011), Multnomah County, where Portland is located, experienced a $10.5 \%$ increase in population growth between 2000 and 2010 (Siu, 2010). From a geographic perspective, Portland does not have easy access to a core fine art city. The closest established fine art core city, Los Angeles, is over sixteen hours from Portland. Both of these factors grant Portland more flexible relationships to the fine art world overall, guarding against the selective hierarchical trends of the system and economic fluctuations.

\section{Regional Culture Builds and Supports Art Worlds}

In addition to the concentration of creative class people in Portland, its semiperipheral economic relationship to the larger art world, and its geographic situation, it is 
also important to consider the ramifications of the culture and history of the underground scene in Portland to understand how Portland in particular fosters the underground art scene. Portland's reputation for DIY culture is key, as discussed in Jason's story in chapter 2. The internet enabled the values of DIY and punk decentralized access to production and distribution in the art world. That is, as artists are able to represent themselves across great distances for free they no longer rely solely on the traditional representation provided by a commercial gallery (Pariser, 2000).

In contrast to core art cities, Portland's reputation for the arts grew more from indie rock/punk music than fine art. During the 1990's the Pacific Northwest was host to the grunge rock scene, a music movement born from punk culture that actively rejects commercialism and celebrates independent work and artistic production, the core principles of DIY culture. The nation came to know the Pacific Northwest through its rejection of large-scale commercialism in favor of small-scale local production, and this created a reputation for the arts in the region. (Prey, 1996)

Portland's well-known DIY ethic explored at length by Heying in his recent book Brews to Bikes. Although Heying does not consider the roots of the DIY Portland ethic, he does illustrate its widespread influence in the growth of the artisan economy of Portland. Heying calls to attention the economic development surrounding handmade specialty items in Portland, contrasting the big industry growth plans that are often proposed as economic stimulus. He finds that Portland's population prefers imaginative unique products from local vendors, including food, beer, craft, fashion, and even leather working. Portlanders support this small scale economy, making the city an excellent place to live and work as an artisan. (Heying, 2010) While fine art culture is only one 
small part of the artisan economy he describes, the cultural value that propels the success of the system is accessible to fine artists in Portland.

This can be illustrated by the success of Last Thursday in Alberta, which draws 10,000 people in the summer every month. The format of last Thursday allows for wide and completely free participation, and provides an audience for many artists who might otherwise have to rely on more conventional promotional channels provided by galleries or reviews. For example, one DIY gallery, Appendix Space, uses the crowd of Last Thursday to attract people to their otherwise hard to find space. The gallery is in an alleyway, and the gallery coordinators make a fire and host the opening so that Last Thursday pursuers can accidentally stumble into the space. The shared cultural dynamic of DIY, diffused from the same Pacific Northwest reputation that brings artists to Portland, functions as a support to the artists in NE Alberta. Thus while the established art world requires reputation to gain support, the semi-peripheral art world in Portland encourages an easier participation as its cultural values favor emerging work and a nontraditional way of showing it.

Conclusion

Thus, Portland's art world is a case with many different factors. In order to understand the lived reality of its artists, a careful examination of the social system surrounding the production of art is necessary. Becker provides the framework for this analysis through his concept of art worlds. Portland's art world, however, does not fit his model and can be explained through additional lenses. First, the technological revolution has changed the structure of art worlds by providing new channels for artists to reach an audience through self-representation on the Internet. Second, the creative class population 
of Portland changes the way that art is supported on a city-wide level. Rather than established channels, the creative class of Portland supports the arts by affirming the DIY ethic that was established by the punk/grunge music movement in the Pacific Northwest in the 1990s. This is the same ethic that fuels the creative ecology in Portland, and creates social and artistic resources for artists working and living in close proximity to one another. The geographic location of Portland and semi-peripheral art city reputation also creates insulation from global economic trends that restrict funding for art in economic downturns so that Portland can maintain a healthy art culture during recession. It also keeps artists in Portland in Portland, rather than filtering them to nearby core art cities. This is the setting for Oregon Painting Society and the underground art scene of Portland. 


\section{Chapter 4: METHODS: ETHNOGRAPHIC CASE STUDY}

\section{Design}

This thesis is an ethnographic case study of an artist collective in Portland, OR. I chose ethnography for several reasons. First, a lack of prior research on collectives required an exploratory component of research design that could identify pervasive themes that collectives employ in conceptualizing, organizing, and maintaining their art. Ethnography was also chosen because it is able to capture the depth of complex social processes (Marshall and Rossman 2006:53) involved in group work and because it provides an opportunity to map out the cooperative links in the art world of collectives first hand. Third, it can incorporate subjective definitions of success and more valid understandings of organizational and conceptual paths to sustained artistic output because it allows members of the collective to define and provide accounts and evaluations of their group in their own terms. Fourth, ethnography is particularly fitting since the structure of collectives is highly varied due to a lack of formal guidelines about how collectives are supposed to be formed, in contrast to business models that follow common formulas, for example. Last, and most importantly, by choosing a research path that followed artists themselves rather than the institutions that show their work, a world of non-monetary cooperative work emerged.

This research was built in four phases, 1) profiling, 2) participant observation, 3) member interviews, and 4) venue interviews. Because each phase builds on the previous by providing greater depth of understanding, data from subsequent phases triangulated data, verifying facts or illuminating inconsistencies in the findings of the previous phases. Thus, the analysis was built on three way verification between phases of the study. First, I 
created a profile of the artist collective based on their website to provide a skeletal map of the art world of a collective and a context to frame initial observations. Participant observation created a strong map of the social and structural functioning of the collective, while interviews completed the picture by providing an explanation of the social and structural processes revealed in the previous two phases. Additional interviews were conducted with people who run the art venues, or places that show art, where OPS has shown in order to develop additional perspectives of OPS' art world.

When I came to choose an artist collective to study, I relied on the knowledge of Harrell Fletcher, Professor of the Social Practice of Art at Portland State University. Having long term participation with the art world in Portland in addition to the national and international art world, Harrell suggested that Oregon Painting Society would be a good match for the project since they were well known and highly active. As an artist collective with recent notoriety that came with a show at the Tate Modern, and as producers of non-salable art, OPS was chosen for both their high levels of productivity and low levels of monetary support for their work. The first contact I had with OPS was after they performed at a venue called Holocene in South East Portland. After their show I approached them, introduced myself briefly, and mentioned that I was interested in studying artist collectives and that that was why I attended their show. They were receptive to the idea, and encouraged me to contact them. I then sent them an email explaining that Harrell had given me their names, and they invited me to a group meeting to discuss the project. After disclosing the scope of the research, OPS agreed to participate and signed consent forms. 
The first phase of the study, profiling, consisted of collecting descriptive information to understand the intentions, history, and structure of the collective. I gathered basic information such as who group members are, when and how they formed, and the publicity that they have received. From the website, short discussions with members, and attending at group meetings. This phase created a general portrait of the collective in the context of Portland, and enabled me to plan a more focused observation period.

Participant observation of OPS made up phase two of the study. Having a context from the information gathered in the profiling phase, my observations focused primarily on how artists navigate the structure that their group has created and how they navigate the larger world of art as a group. My observation of negotiations of a group project, allocation of time, production of art, and showing of art revealed both social and structural processes that contribute to artistic sustainability. That is, this phase revealed the cooperative links or elements that make up the OPS' art world and the kind of social processes that characterize them.

Next, in-depth semi-structured interviews were conducted with each member of the collective in order to understand the member's conceptualization of the cooperative links found in the observation phase and to deepen my observations of group work by elaborating the effect of group work and each member's work. This phase allowed me to develop a deeper understanding behind the social processes observed in phase two. I chose semi structured interviews because it allowed group members to provide their own personal interpretations of their realities (Charmez, 2006:24) Group members offered insight into the motivations behind forming a collective that a map of the structure of 
collectives cannot. Thus, while the participant observation answered the question- how do you do art in cooperation with each other, the interviews were designed to answer the question- why do you do art in cooperation with each other? These interviews explored the ways that the collective facilitates the artistic output of the artists involved in it. Member's perspectives are especially important because they reveal the connection between individual levels of artistic output and the nature of group work.

Additionally, the interview questions focused on the relationship OPS members have to the rest of the art world. These questions helped to illuminate the kinds of interactions members have with both established art world and with the more informal underground art world. This portion of the interviews answered the question, What does OPS' art world look like?

Finally, interviews were conducted with non-members who made up OPS' art world, particularly people who run venues that show art. This phase of the research expanded the conceptualization of the artist collective's interaction with their art world and verified the values in the underground and established systems. This phase was a final verification of validity for the previous phases.

\section{Site description and Participants}

Oregon Painting Society (OPS) was chosen because the group is an exceptional example of what successful art career without monetary support looks like in a city that provides alternative kinds of support. Although their success is exceptional compared to many of their peers, their cultural involvement in their surrounding art community speaks to their representativeness of the underground art world of Portland. That is, while they clearly have talent and an unusual capacity for navigating their art 
world and being recognized, they are still representative of their peers in terms of lifestyle, values, and methods for making work since they are culturally entrenched in the underground through neighborhood and social ties. Working with them enabled my data to show what success looks like and how the culture of the underground contributes to it.

Established in 2007, OPS is an artist collective based in Portland. There are five members, four members aged $24-26$, and one member who is 43 . There are three men and two women in the group. All members hold college degrees, and three members graduated from the same art school where they met. None of the members have children and are not married. They are also native to the Pacific Northwest, and grew up in Seattle, Olympia, or Portland. All of the members work part time jobs to support their art careers- two members work at a daycare, one member assists a lamp maker, one works at a video store and a distillery, and the other grades ACT tests. Notably, the members of OPS are able to support their work through meager part time earnings because they have few financial obligations such as supporting a family or aging parents.

OPS is anything but a group of painters. Their shows often feature re-claimed and re-invented found materials, home-made instruments, costumes, performances, installations, and even short films. The statement on OPS's website explains the collective:

"The group has produced interactive audiovisual environments, recordings, and performances. We are compelled by The Mystery to forge possible doorways into impossible worlds. Transcendent creative collaboration is both our method and our goal."

They list ten exhibitions, thirteen performances, one residency and one invited workshop since 2008 on their website. They have enjoyed a considerable degree of 
attention from media. OPS have been featured in Italian Vogue, in addition to performing at the Tate Modern in London last year. They were recently voted "most over-shown artist in Portland" by PORT, an online Portland arts magazine, reader's poll awards. Reviewed extensively in Portland local publications like the Culturephile and PORT, OPS has also been featured in international reviews including Russia, Norway, and Australian newspapers. (Oregon Painting Society, 2011)

Membership in the group is crystallized. Since the group's inception there have been several members have left and others have joined the group. Although in its beginning stages the group consisted of anywhere between two and ten people, there are now five members and the group is no longer open to new members. All of the current members have been in OPS since its founding. OPS members explain that like a band, their group membership formed naturally based on common interest and artistic compatibility but now has an established dynamic that could not easily house new members. However, they do collaborate with other artists of groups of artists for individual projects.

Each group member contributes to the artistic process, and there are no formal roles, titles, or hierarchy in the organizational structure of the group, which is consistent with the DIY values in chapter 2. Four out of the five members live in the same house, and the fifth member lives close by. Most work is done at the house; the group does not maintain an outside studio space. The house is located in the Alberta Arts district of Portland which has a reputation for experimental art and has a large population of artists as well as cheap housing, bike friendly roads, access to public transportation, galleries, cafés, record shops, and an active night life. 


\section{Data Triangulation in Research Phases}

Phase One- Profiling November 2010

In order to develop a context for my observations, I conducted a short latent content analysis of OPS's website including posted reviews of their work from local and international sources. Latent content analysis is an effective tool for interpreting the context for a group (Marshall and Rossman, 2006:108) To do this, I printed the pages included in their website and jotted notes directly on them and highlighted pervasive components of the site. This illuminated how the group presents themselves publicly and how the role of the critic plays out in OPS's art world.

The most important discovery of this phase of research was the role of the online presence of OPS. For instance, I found that OPS posts some projects on their website that are online projects only. In addition to films of all of OPS' live performances and audio tracks of OPS music, there are several films that were not intended for live showings but rather just for online access. This was an important window into understanding OPS's cooperative art world in which art was posted for free in its original format without any intention of selling it, to be accessed by a wide audience rather than the local audience art goers in a traditional commercial gallery setting. The website demonstrated the decentralized art world that values independence, rather than gallery representation, as it is designed and is maintained by OPS members.

Phase Two-Observation November 2010-February 2011

Because the project is exploratory, I conducted a sustained period of observation to find pervasive themes and processes that supported artistic production. Observation was the second phase of the study and consisted of about thirty hours of observation over 
a period of four months while OPS created a film project for an exhibition at Portland State University's AB Gallery on February 3. During observations, I kept two field journals which I typed within three days of observation. One journal contained observation notes, while another contained memos pertaining to my reflections or theory building.

My observations enabled me to build a complete picture of each step of the project for the Portland State gallery. I observed OPS whenever they met. Meeting times were arranged according to everyone's outside work schedules, and ranged from five hours on a Friday night to two hours on a Tuesday afternoon. OPS meets without regularity and work is done without some members present. Because they sometimes work on group projects individually, I asked to be invited to observe their work when at least three members were present. I observed group meetings accompanied by group dinners (which I participated in), set building for the film, the filming process, film editing, the opening night of the film, and the celebration after the gallery opening. Due to scheduling constraints, I was unable to attend one of their meetings in which they did a large portion of this filming for the project.

The observations were particularly important in revealing the social dynamics within the group. In group meetings I was able to observe the informal social processes at work that contribute to sustained production like interest and support for other group member projects and humor during brainstorming sessions. I was also able to observe the way that the group created art with each other. Always informal, they traded roles such as shooting film, building sets and acting in the film in addition to teaching each other necessary skills for the project such as video editing. 
The observations also revealed and how OPS interacts with the other actors in their art world. At meetings there were discussions of who had contacted the group about showing art, updates on grants that they had applied for, and sometimes an unscheduled visit from other artists (friends) from the neighborhood. During these observations, differences between two kinds of art worlds that OPS interacts began to emerge- the established and the underground. It also revealed the role of social relationships in in the informal art world as they provided the basis for several opportunities to show art.

\section{Phase Three- Member Interviews February-March 2011}

At the conclusion of the observation phase, in-depth interviews were conducted with the artist collective. Using concepts gained during the observation phase, I interviewed all five members of OPS separately about their individual artistic production and their art world. These interviews followed a semi-structured approach. Although there were several predetermined discussion topics, the interviews were designed to have enough flexibility to explore concepts beyond those found in my observations. Additionally, since much of the work that OPS does is based in informal social relationships, a conversational interview style was appropriate and comfortable for the members. (Marshall and Rossman, 2006:101). These interviews were digitally recorded and transcribed directly afterwards.

These interviews provided rich personal descriptions of interactions within the group and with the larger art world that helped to explain the factors contributing to artistic sustainability. They focused on the transition to collaborative group work, goals of the members as artists, and experiences with showing artwork. Particularly, the interviews illuminated the boundaries of the established and the informal art world, the 
benefits of group work from both a social and artistic perspective, the social origins of the informal art world, and the values and conceptualization of artistic success and artistic identity.

This phase also served as validity check for the observation data. During these interviews, I shared the preliminary map of the art world of OPS and the member's defined kind of venues of their art world that I had not directly observed to make a more complete picture of how they navigate it. This collaboration also created transparency, as the interviewees were able to evaluate my work the interviews became rich with stories and thoughts about how they interact with their world including uncovering connections between the established and the underground art world. I found that by sharing my preliminary analysis, the members became more comfortable discussing my questions. This created a better relationship between myself and the members and a more interactive way of gathering data.

Each member was recruited at the beginning of the observation phase, and interviews were scheduled after its completion over a period of one month due to OPS member's busy schedules. One interview was conducted at a coffee shop on Mississippi Street, one in the Sociology department, one in a member's individual studio space, and two were conducted at the OPS house. These locations were chosen by the members and were based on their convenience and comfort. Interviews lasted between 45 minutes and 90 minutes. Appendix A gives the interview guide I used.

Phase Four- Art Venue Interviews April 2011

After the interviews with OPS were completed, interviews with people who run the art venues that OPS accesses were conducted. These interviews were integral to 
creating a valid picture of the art world of OPS. They verified the values and practices of the people in that system. This stage of the research helped to illuminate the differences between the established art world and the underground.

I conducted semi-structured interviews with three key actors: one gallery owner, one gallery coordinator and DIY gallery owner, and one DIY residency/gallery co-curator who were selected by snowball sampling though suggestions given to me by members of OPS. These interviews lasted for about one hour. These interviews focused on how the gallery choses artists and approaches exhibitions, and what participants thought about the art scene in Portland. See appendix B for the interview guide.

\section{Data Collection and Analysis}

Data collection and analysis was conducted with a high degree of transparency and cooperation between OPS and myself. Before beginning my research I revealed the scope of my project, and OPS agreed not to have access to my notes written during observation as possible documentation of in-group conflict might be a source of emotional strain for OPS. I shared my preliminary findings and OPS discussed my analysis with me throughout the project because they repeatedly engaged with me while I was present, asking questions about what I was going to write about. Initial discussions revealed that they were also interested in the meaning behind the kind of work that they do and meaningful conversations about the importance of cooperation were a regular part of my observations.

An expectation of transparency was established during the first group meeting, when the key informant introduced me as a project collaborator although their project itself was in no way influenced by my direction. This made sense considering the 
collaborative process of OPS's art work. As my observations progressed, the members began asking increasingly pointed questions about my perspective and were eager to discuss it. They revealed investment in cooperative arrangements that I found common in the informal art world, and were quick to point out where they thought inconsistencies in my findings were. This kind of discussion was not unexpected, but not initially prompted and contributed to the coding of my interviews and to my theory construction.

\section{Note taking and Recording}

I took hand-written notes during the observation phase, and then typed them later. This phase revealed pervasive themes that formed the interview guide. Themes I found during observation were how to work together, mixing social and work time, balancing work and other artistic priorities with OPS work, reaching an audience, funding projects through group contribution or grants, and cooperating with each other and other artists.

All five interviews were digitally recorded and transcribed soon after in order to provide preliminary analysis that guided subsequent interviews. Because the interviews were semi-structured there was variation in each interview. Much of this variation was directed by the members of OPS. I asked each interviewee to let me know what questions or phrases seemed particularly pertinent or irrelevant to his artistic production as I asked them. This interactive interview style created validity and added depth in responses that communicated a high degree of engagement with the project. Starting with the second interview, I included questions about Becker's theory and gained rich information from their reaction to his conceptualization of the commercial art world. During the third interview, I incorporated a preliminary map of the informal art world, the interview lasted forty-five minutes longer than I expected and generated a list of contacts of people who 
maintain underground venues in addition to identifying additional actors in informal art world that I had not previously been aware of.

\section{Coding}

After the first three interviews were completed, they were coded in order to glean key themes of OPS and to revise and focus the questions for subsequent interviews. Using colored highlighters, they were coded based on four emerging themes: success, professionalism, what it means to be an artist, and how to show work. These analyses were not shared with subsequent interviewees to ensure unbiased data. These themes were consistent with those found in the subsequent interviews as well. These findings are discussed in chapter six.

At this time, I coded the interviews in term of kinds of artistic and social resources that the collective provides its members. These themes were also consistent in subsequent interviews.

The three interviews with gallery representatives showed sharp differences between the established and the underground gallery perspectives. The first interview illustrated the commercial gallery model. The second illustrated the values of creative ecologies. The third interview with a representative with one foot in the established world and another in the underground illustrated both. His perspective verified the perspectives of the other two interviews, and helped to explain the connection between the established and the underground art world in Portland.

The interviews were coded for values that reflected the comparisons between the underground and the established art world. These codes verified the validity of the comparison as responses fell squarely into these categories: organizing principles, 
audience, methods of promotion, medium of work shown, and national versus local cultural perspective, and whether or not Portland was a good place to do art.

\section{Researcher role}

The culture of OPS is similar to the culture of my artist friends. As I started the research, I realized that in some ways I was an "insider" as I could follow some conversations about bands that they liked. We shared similar stories from college, and even ate similar food. I was familiar with the informal process of making art in company of others as this was something that was common to my college experience. However, my total lack of involvement in the Portland art scene was apparent as I was unfamiliar with many local or regional artists or bands that were known to the group. Also, since much of their art world is based on social ties, our lack of mutual friends made me an apparent outsider. Thus, my entry into the field was sensitized, but I was not perceived as an insider in the world of art that they knew.

As a participant observer, I helped whenever I could. During one session, I helped to build the set for their film by stapling plastic sheets to the celling of their basement in order to create a space-ship. After helping to clean out the basement so that they could begin transforming their space, I accompanied one member to the dump. I attended one member's Christmas party and met some artists from other social circles, and got a chance to spend time getting to know members outside of my researcher role. Since the informal art world is based in social relationships, this kind of rapport building was particularly important and established trust. 


\section{Chapter 5: FINDINGS PART ONE,}

\section{ARTISTIC AND SOCIAL RESOURCES IN THE COLLECTIVE}

\section{Introduction}

I began the project with the expectation that the organization of an artist collective would have a large influence on its success. My anecdotal evidence told me that unorganized artist collectives struggled. I expected collectives with clear roles, goals, and established routines would be successful. However, my first day of observations proved me wrong. OPS has no formal roles, titles, work schedule, method, decision making process... nothing! More than its organizational capacity, OPS succeeds by providing both artistic and social resources for its members. In other words, the network of support that the group provides to each other proved more important. I define artistic resources as those factors that directly related to making art- materials, skills, time, networks and evaluation. I define social resources as support and informal work environments that allow for artistic production.

In the absence of regular funding for their work, these resources are incredibly important. In comparison to other kinds of creative workers, artists have fewer small scale earning opportunities. For example, members of a band often have an opportunity to support their work financially through cover charges or a percent of bar earnings at a venue where they are playing. This income is easy gathered from peers attending their shows since it only requires a small amount of financial investment from each person attending shows. Artists do not have normalized financial support from peers. Furthermore, while other European countries and Canada provide support for fine artists through subsidies and income support, American government provides little aid for 
working fine artists. Although there are grant opportunities for artists to make public work, this is hardly the genre of OPS and other artists in the underground whose contemporary work does not fit the scope of projects commissioned for public buildings or space. Members of OPS substitute group and community support for these resources. This chapter focuses on how work in their collective facilitates their ability to create this alternative support.

My findings in this chapter focus on in-group dynamics, and their role in supporting sustained artistic production. These resources offset the challenges that individual members face in doing art. OPS members emphasize these benefits. Being an young artist can be discouraging and work can be difficult to do, especially after school is over as one lacks studio space, supplies, and community. Working in a group is a way of making managing time in the midst of multiple priorities fun and doable. This helps to ensure continued artistic output by securing an inviting environment to work.

\section{Artistic Resources}

OPS members share artistic resources as equals. Everyone shares ideas and generates new concepts together. This structure is instrumental because it is the source of their continued motivation to work together and the sustained quality of their work. They also provide constant feedback and critique of the project throughout the creation of new work based in trust and shared priorities. Because each group member is invested in the project and in each other, it is easy to provide quality feedback about the work without the members feeling challenged or offended by criticism. Disagreement is replaced by collaboration. 
The group also shares material artistic resources. When working on a project, members of the group share both the cost of new supplies and bring more expensive tools, like a video camera or power tools to the project. Because they share what they have, they are able to do what no individual member could afford.

Members bring skills to share. One member is especially good at building instruments. Another is a great website designer. This saves both time and money as at least some of these things would have to be sub-contracted by an individual artist as Becker's Art World suggests. Importantly, they also maintain the progress of the project by giving the time that they have. With part time jobs and other artistic priorities, they provide one another with a safety net by working together. Because they share, they are able to get work done on time.

Finally, members also bring different social networks to the group, which is particularly important to the DIY scene to be discussed in the following chapter. These social networks connect OPS to a larger social world often engaged in making and showing art as well, gaining them both supportive peers and increased opportunities to show their art.

\section{Collaboration Generates and Improves Ideas}

OPS is a collaborative group. They share the work load and creative input on their projects. Working collaboratively keeps OPS's ideas fresh and flowing easily. Members have established a trustworthy process for coming up with good projects. This group resource is a form of social capital, and it enables coming up with good ideas quickly and sustains artistic production. 
OPS begins projects with a brainstorming process. To start their video project, members sat in their living room and bounced around different ideas for about an hour. Ideas ranged from a Japanese game show with the members of OPS to a series of portals that lead to other dimensions. Once an idea was offered, another member would add to the existing concept, or tweak the idea to make it more compelling. In this way, the final set of concepts was not derived from one member, but from all. Ideas became more developed because of group involvement. Lightheartedness was a key element in the process, and laughter was the most common response to ideas. However, by the end of the hour, a preliminary project plan was in place. One member explains how ideas are easily passed between members of the group,

"it helps when you get really close to certain people in a group... certain ideas will just come to you naturally because you are used to this certain world that ... everyone has built... We can relate to each other through social cues and through humor and little ways of looking at things. The more we talk the more [a project] gets... molded into itself ...then when we were making art together it's like we are traveling to this other world... that we all understand as deeply as possible." [Artist 1]

Coming up with ideas together is rewarding for the members of OPS because it makes a hard process fun,

"the more we do it the more easy it is... logistically and inspiration wise...we never need to warm up. You get two or three of us in a room and we're just going to come up with an idea of something in any medium that we put our minds to... like a band it's really gelled." [Artist 5]

Thus, not only is the process built to enable better project ideas, but it is also empowering. It is a way to expand the parameters of thinking by incorporating new ideas that you would not have come up with, and a way to take on the project together rather than alone. 


\section{Continuous Critique Based in Trust and Love Makes Better Art Work.}

The process of critique, a familiar element of art school, often comes after the completion of a project, from reviews of a show in outside sources like newspapers and magazines. OPS, while still receiving critique for shows, also engages in collaborative critique with each other from the beginning of an idea to the showing of a project. With multiple people in the group, a constant critique occurs throughout the project, making the work stronger before it is shown. Additionally, the in-group critique that OPS engages in is based in long term familiarity and trust among the individual artists so it is more honest, informed, and gentle in a similar way that critique happens during art school. Working together is based in mutual priorities and care for the other members, "[learning to work together] was just kind of this process of... well, we were all excited enough that we wanted to try and loving enough to be patient." [Artist 2]

This contributes to artistic production by creating a safe but honest way of approaching a project and a better end product that is more likely to attract attention and more opportunities for showing work. Members explain how critique is well-received because of the closeness of the members,

"everybody has gotten to a point where everyone sort of listens and if it doesn't seem that cool... ideas just kind of go out the window...so it's not so painful ... it's not so devastating for your idea to get crushed. we have reached a point where ideas just flow really quickly because we are used to this certain...pace, and we are used to each other, and our likes and dislikes, so feelings don't really get hurt that often, pretty much ever, so it flows really naturally" [Artist 3]

"I think the fact that we are all close just makes it easier to talk and critique the group without worrying about offending someone... if we understand each other's sensibilities it's not like critiquing an idea is like attacking the person." [Artist 4] 
With the shared priority of quality work and the closeness of the group, OPS members give critique without stress.

Sharing Supplies and Skills Saves Time Money while Increasing Artistic Versatility

Another important resource that contributes to sustained artistic production is the sharing of supplies and skills that are needed for both group projects and individual work. While individual artists might have to invest in expensive supplies like computer programs or video cameras, between five members of the group someone is likely to have what the group or an individual needs to finish a project. This way, the parameters of projects are broader without an increase in total costs. This is particularly important to OPS because their projects are either barely funded by others or completely self-funded. The group has a pool of skills for use on projects or to help each other in individual pursuits, like web design or electrical wiring knowledge for musical instruments. They can collectively execute a variety of kinds of projects that no single artist would have all the skills to do. As a result, OPS has great versatility.

"Art is expensive to do, it's hard to do... it can be very labor intensive, it can be very costly, and self-financed... [OPS has] the ability to execute big projects because there are five people pitching in, there are five people unloading the truck, there are five people buying materials, there are five people looking for materials, there are five people telling their friends about things we do... you know, the thing just exponentially grows." [Artist 5]

'I'm like, 'who's going to design my website?' and [as an individual] I have to figure that out, and with the group thing it's automatically taken care of, so there's this kind of practical... exponential ability to do things without having to wrangle people and bands and help and pay people." [Artist 5]

Several observations illustrate the benefits of this kind of sharing. The film project required several sets of skills and expensive supplies, including materials to 
construct a set, a camera for shooting the film, and a computer and program to edit the film. The operational knowledge about how to build, film, and edit was also necessary. Although only one person owned the film editing computer program and had the skills needed to use it, she shared her computer and taught the other members the basics of the program so that they were all able to work on it. Another person owned the camera they used to shoot the film. They had purchased, found, or re-purposed the materials they needed for building, and they had all pitched in to buy large quantities of paint that they used to make their set. One member's truck was used to transport another member's large paintings from his studio to the gallery where they would be shown. This access to skills, tools, and supplies makes projects, both group and individual more doable. The process of continued artistic production is less challenging through social support. Time and Project Management as a Group is Easier than Alone

Flexibility is another important requirement to artistic sustainability. Because there are five people working on a project, it is easier for each individual artist to work part time with OPS, other artistic projects, and part time for pay. The members are able to get projects done in a timely fashion when they work together. They set a pace for one another, and they are able to work when they are inspired and able to. This sustains and increases production because members can step in for each other.

"I think it would be awesome if more people showed all the time and I think the reason that they don't is because it's hard to show that much as an individual but it's easier to keep up the momentum. If there are other people... you can get more done faster... I think if there were other groups that worked collaboratively they would probably be showing [their work] all the time too." [Artist 1]

"If [some of us] are going on tour for half the time we are working on some project then [the rest of us] step up and we kick ass and then when they come back they just bust ass for a week and get their name on it, their hands in it, and 
their ownership of it. You just do what you can, we all have schedules, we have other things we do, they have bands, ... [or an] art group, and so it's just kind of how it unfolds." [Artist 5]

"once the idea is there, one person can work on it while the other person is away, so it's kind of like this jellyfish blob, ...some tentacles are busy while other tentacles are able to do the job or whatever and so it's effective and efficient and $i$ think that the level of communication that we all have is part of the reason why it works" [Artist 3]

"as we are getting closer to a project... one of those people at some point is going to really going on the project... or someone before it's too late is going to be like, 'oh man we really have to get to work on this'... we just all kind of have this intuitive sense of knowing when is the perfect time and that we will have enough time. As a group we always get it done...we all can sense when the time is right to really just like get going on a project and that... makes a less...anxious [process]... I trust the group mentality a lot." [Artist 3]

I was able to see OPS's group work in practice. While two members were playing a music show, the others continued to work on filming the video. When it came time to edit the video, one member was occupied by finishing paintings for an individual show, so the others took on the role of editing. Based on schedules at their part time jobs, members picked up where others left off and set goals for completing stages of the project based on everyone's priorities. This made the process flow quickly and easily, keeping the workload manageable and making it possible for everyone in the group to take part. Shared Networks Means More Showing Opportunities

Another important resource that the group provides is a broad social network that enables them to reach a larger audience that is receptive to both individual work and OPS projects. Being able to secure fulfilling outlets for artistic production is a major factor in sustaining artistic production. Members explain how working in OPS helps them to show work, 
"It's very practical because I'm not that social really, so I'm more focused on making the work or something... some people in OPS are more social than me, so that obviously leads to way more showing opportunities than I would have had. Everyone has their own sphere." [Artist 2]

"I feel like artists are... more likely to find the music I do more interesting than music fans because most of the music I am doing now doesn't have... vocals or ...sometimes there is no melody, ... [and] in art there is a whole huge amount of literature about... questioning meaning and ...how its constructed, so... I feel like the very small audience for my music in Portland is more able to be focused because of OPS and I am able to hone in on the type of person that is going to be open to it because I work with artists" [Artist 4]

"success in art is rare...it's very difficult and it comes and it goes and you know, it's cruel, and it can make you feel indignant sometimes... it's cool to have artists that you feel like... god, any success they had I would just celebrate 100 percent and any success they have only benefits me, hell, we are in a group together... we are in it together, and you know all ships will rise, there is way more potential for different ways for people to discover what you do, it's all mutually beneficial, everything we do is beneficial. If [one member] goes on tour ... for a month and he can't be a part of OPS, well, he happens to be going across America and telling people about OPS so you can't lose no matter what happens, it's just win win win all around. If $i$ got huge as a painter, [another member] would find people through me, if she had it huge, people would find me though her. It's awesome." [Artist 5]

Contrast this mutually beneficial relationship to the way that a commercial gallery system supports artists. In commercial establishments with limited space and time to show art, artists are put into competition with each other for a place in the gallery, the situation is zero sum. In the case of OPS, this competitive relationship is replaced by a cooperative one, the better one member does, the better all the members will do. This is also typical of the underground art scene that OPS is a part of, which will be discussed in chapter six. 


\section{Social Resources of the Collective}

\section{The Group Provides Support for Making Art}

When monetary support is slim to null, social support for making art is essential. Without regular primary income from making art, making and sharing it is the major reward. Since the time spent making art must also be juggled with income priorities, it is important for members of OPS that the process of art making is relaxed and intrinsically rewarding.

As a group, they support and encourage each other's art work. Although they all make art together, each member also makes art or music in other groups and individually as well. Members of OPS attend each other's individual shows, and provide verbal feedback about ongoing projects, similar to the feedback in close art school communities. Members describe the benefits of having each other to support their art,

"There is this shared camaraderie... in your unknown period as an artist you really have to gird yourself and find strength to go on and... at my lowest ebbs I can really feel bad about myself...but ever since I have been in OPS I am always like, if those people like what I do, and they are the best artists in the world...it's got to be good. And that's a huge, really important thing, just that sense of support. And also it's purely fun to hang out with them too." [Artist 5]

"It's like kind of like art school never died or something. you still have this group of creative peers to bounce ideas off of and show each other what you are working on" [Artist 4]

During my observations, I saw social support in action. At the beginning or end of OPS work sessions, at least one member showed what they were working on, or told someone about another project. They were all excited to see what the others had been working on, and provided feedback to each other regularly. 
This support was also provided in feedback about group projects. Members constantly provided support for what others had done in the projects that they did together, by complimenting each other's contributions and by showing enthusiasm. This is important to artistic sustaining commitment to doing art. Making Art is Fun, Social and Work Time Blurs

OPS blurs the lines between social and work time. One member said, "We party as our meetings all the time”. Between OPS members' multiple projects and balancing part time jobs, there is not much downtime. It was not unusual for work to be accompanied by beer and dinner. Members emphasize that they are friends first and foremost, who decided to form OPS because they were already working beside each other, and they wanted to be able to do it together. Member's lighthearted, informal relationships decreases stress levels that come with a busy schedule. It keeps doing work without pay worthwhile. Members explain the benefits of working and socializing, "It is motivating to do work because you get home and [one person] is working on something and [another person] is working on something and you are like 'whoa people are doing really awesome shit. I should do something awesome too', whereas, if you just come home and you are by yourself then you might not get that motivation, or if you live with people who are just flipping TV, you might just do that too" [Artist 4]

"It's kind of nice because socializing... fits in with the process of doing the work. It's not like when you are working on something alone and you...have to separate off working and socializing, 'well I'm working now but I'm going to call my friends and go to the bar or something', but in OPS getting together and working on something is in itself social, so it...dissolves that split in certain ways" [Artist $4]$

“We just don't do a lot of chilling and hanging with [other] people, we are just always working on projects, it what we want to do, ... we are super tight friends, we want to spend tons of time together, we are going to have to do projects, and you put a name on it ... and it's called an art collective because that's what people understand it as" [Artist 5] 
"In terms of art, it's the greatest because I feel like it is just so much more creative, infinitely, and exponentially. It's way more fun. If I was a serious artist and not doing work with other people I would just like drink coffee and ... never leave my room and be a complete freak. It's enough like that as it is, except that I do it with at least some other people, and I still don't see people very much outside of that." [Artist 2]

Contrast Becker's model of the art world, which prizes professionalism and uses competition to feed motivation to produce quality work. Rather than choosing a professional individual path, group social support keeps OPS making work.

\section{Conclusion}

This chapter shows that group work facilitates artistic and social resources that support members of OPS in making art individually and together. By sharing ideas, critique, skills, supplies and money, members of OPS make work doable because they are able to achieve an inspiring work environment and high levels of artistic versatility. They are able to combine social networks to reach a larger audience rather than relying on their small personal networks. This provides additional motivation for completing projects and increased visibility in the art world. They also support each other emotionally, providing feedback about work that keeps members spirits high even without financial reward for work that they are doing. Work and social time blur, making projects fun and worthwhile to balance their part time work and other artistic projects.

These benefits of group work contrast the competitive funnel that the established art world that Becker describes. Instead of making individual successes most beneficial, members of OPS are able to cooperate and help everyone involved in the process. While the established art world system rewards individuals who out rank their peers in the opinion of critics and galleries, OPS members have an in-group system that rewards 
every member for the success of any member involved. Group work makes work more doable and success more inclusive, supporting all the artists that participate. 


\section{Chapter 6: FINDINGS PART 2: VALUES AND THE UNDERGROUND ART WORLD}

\section{Introduction}

This chapter explains how OPS is integrated into the underground art world. The most salient findings revolve around cultural values that OPS shares with the underground art world that contribute to sustained artistic production. These values inform the way that the underground art world functions as a system; they form its ideology. Ultimately they explain how doing work detached from income is meaningful by framing what being an artist means to OPS in practice and conceptually.

First, I will discuss the how OPS members conceptualize what being an artist is about. This is important because it contrasts the definition of success and professionalism present in the established art world, and replaces old notions with new boundaries around what it means to be a legitimate member of their art world. Then I will discuss how these values are shared with an underground art world that OPS is deeply rooted in, primarily as they reorient thinking away from the concept of art or sale and towards the concept of art for art sake and art for showing.

I decided that the best way to begin was by listing and locating the shows, performances, and exhibitions that OPS has done. During the profiling phase of my research, I made a list of the places that they have shown, and began trying to understand whether these places had something in common with Becker's commercial gallery system explanation. My observations did not provide data pertaining to OPS' art world because they focused on one show rather than a longer span that would include multiple 
venues where OPS showed their work. However, during interviews with OPS members, I asked about the kind of relationship they have to the places that they have shown.

\section{OPS' Values}

OPS members describe a different set of values surrounding what it means to be an artist than those that Becker describes in the commercial art world. These values explain how cultural validation for doing serious work for little financial reward happens by creating boundaries for explaining what an honest, serious, career in art looks like. This separates the artists in the underground working without financial support from hobby groups and establishes a code about what a career without money making art looks like. These values, that success means making and showing work as much as possible, that showing is about expression rather than reputation, that the term professional is irrelevant because it carries financial implications, and that an artist is someone who reflects and expresses are the values that form these boundaries.

These boundaries also validate the way that the underground art world functions, and reinforce the system by explaining its underlying ideology. Specifically they reinforce the ideology that making art without anticipating financial reward is valid, and more than that, a better way to do work. Importantly, although these values disconnect art making from profit, members of OPS do not oppose making money from art. These values however, do mean that making money is not the priority of their work, rather the art is. In other words, this value set supports the idea of art for art sake rather than art for sale as Becker's commercial art world suggests.

Additionally, the values surrounding what it means to be an artist in the underground art world are meant to be challenged. That is, while Becker's art world 
prizes professionally established relationships, this world seeks to push boundaries of both art and how to make it. Breaking rules was often discussed in positive light by both OPS members and by the DIY gallery owners I interviewed. This keeps the boundaries fluid and changing, rewarding the unexpected over the usual and developing a resistance to established culture.

Success means making and showing art as much as possible

OPS members consider a show a success when it has met their own artistic standards and when they have reached an interested audience. They evaluate the art that they produce in view of the artistic impact of the project, rather than the prestige of the place that the art is shown or the reception of critics, the way that Becker's commercial gallery model would suggest. This concept of success is important because it allows any show to be potentially successful and to be meaningful and valuable to OPS. Members explain what success means to them,

"[Success is] to continue to make work that you feel is really good, which is obviously our goal, so having lots of shows spurs you to do that." [Artist 2]

"[Success] for me it's just, did we do our best basically, is the main thing. Always if a good amount of people came we are happy for as many people to see the show as possible. If someone buys it or not is not something we think about a lot because not all of our art is very purchasable. If someone does it's always incredible... and a surprise and it's awesome, but if we are done and we are like, 'oh my god we made something really awesome that we like' then that is pretty much what makes a really good show or a show successful to me."[Artist 3]

\section{Showing is About Expression rather than Reputation}

This is not to say that showing work anywhere is the criteria for a good show.

OPS ultimately determine whether or not to do a show based on the available space and resources of the venue. The artistic outcome of the show is the top priority, and if a space 
cannot accommodate a project they want to do, they turn down the offer. This places greater emphasis on the art than the reputation of the place where you show it, which rejects Becker's concept that showing art work is linked to the reputation of the place where it is shown. One member explains,

“Sometimes people will be like 'you should do a thing in our gallery' and you will get one wall space and it puts a lot of limitation on what we can do, and so really we feel like it's worth it when it's pretty open and if we have a lot of space to work with...that's a plus. And if they can help us out with... getting materials, then that is a big plus, we don't want to go in the hole doing a show, you know?" [Artist 4]

In this instance, two members describe two offers from the same venue, and how they decided to accept one and reject the other,

"Some places allow you to have sound through a PA and an audience will come, and some... you can do an installation in a month in this space and then people will come, you know? Holocene asked us to curate a night, and so we chose some of our favorite musical friends and then we wanted to have the whole thing be really experiential, like an installation that we would do...and they were part of our whole system for the night, and we all played music simultaneously in the installation that we did." [Artist 2]

"well, it's worth it when ...we are going to have the...resources to do something that we think will be awesome... like, every year we pass on this thing at Holocene where they want you to construct a miniature golf thing. They want a bunch of different like artists to make a hole and then people can go and play mini golf and it's just like, well that doesn't feel like it's worth our time because it's just going to be a bunch of drunk people playing mini golf and if we are going to take the time or put all of our focus and energy for several weeks into [a project] then we want to be able to realize something." [Artist 4]

While the art world that Becker describes prioritizes the reputation of a gallery over the kind of space and resources it offers, OPS is more interested in the degree of artistic opportunity presented in an offer to show work. This refocusing of priorities is an 
example of how the art work itself takes precedence over its established art world context.

The term professional is dated and lacks practical meaning

OPS members felt dissonance with the term "professional". The idea of a professional artist carries an unclear meaning to the members of OPS, some feeling that they are professionals and some not. They describe public perception of being a professional artist as an income related title. Although they each re-iterated that they are serious artists with the practice of making art as their primary work and career, they explain that the implications of the term suggest that this seriousness must be accompanied by monetary support.

Members think that the term professional is dated, and that the concept of making a regular income from art rarely happens. For OPS, one's work is not necessarily connected to making a living. Furthermore, some members actually prefer not to be considered a professional, regardless of monetary support because the nature of their work does not fit a typical career model. One member explained that if makes just as much sense to classify the Rolling Stones as professional as it would to classify OPS that way, the term just doesn't quite apply because the work is not approached with professional standard especially from a business perspective. Members explain, "Sometimes I [consider myself a professional] and sometimes I don't. I think that I do in the sense that a word can change....Technically I do not make money making art but professional artists can also be seen as someone who is serious and I sort of relate to that. I think I am a professional artist in that sense, but not making money yet. I think it's just a commitment to it or something. And if you are thinking of it like that then I would say yes. "[Artist 3] 
"[I do not consider myself professional] because I don't even come close to making a living from the creative projects that I do and actually there is something about the idea of the amateur that I kind of like.... the idea of trying to keep an amateurish enthusiasm about the work...amateur can be used as a pejorative term a lot but... I don't really like the professional, 'my art is my work and like I treat is as a business' sort of model. I prefer to try to keep it as something that you do with your time that's special and is not just boring drudgery." [Artist 4]

"I consider my main focus to be working on art all the time. I have a day job that I work one day a week, and that's why I live here and why I have food stamps. I mean, I need money to live but just as small amount as possible.... and maybe later I will make money off of [art] or not, but when people ask me what I do I always answer that I am an artist, not that I am a day care teacher... The word professional implies money in some way... and it's just not a word that is relevant because of that...That's not what making art is about, obviously. "[Artist 1]

"I guess the term professional is weird, ...but yeah I do, definitely. I approach [art] as a career and a practice that I want to make my total, I would love to have my time be spent exclusively on art, as far as making money... basically what that means is a seriousness. I've shown work in my city you know, every other month for two years, so that's a serious showing artist who has as working studio, and I put in more hours here than any other job I have, so yeah, I think you would say that's a professional artist in the sense that professional also indicates serious." [Artist 5]

The dissonance with labeling themselves as professionals that OPS express is a direct departure from the commercial gallery system model that Becker explains. In a more credential based hierarchical model, professional standards, presentation, and monetary support are key elements in the process of showing art since galleries and patrons expect it. By departing from that model, OPS is able to judge their artistic merit based on the time and seriousness with which they do their work.

An artist is someone who reflects and expresses

Since the standards of a professional artist are not applicable to OPS members, it is important to consider what being an artist does mean to them. During interviews, I 
found that members approach the concept of being an artist from the perspective of having a creative state of mind and spending a large amount of time doing artwork. Again, this definition of artist is centered around the making of the art itself, rather than selling work. Of course, this is not to say that the artists that are part of the established Becker art world derive their motivation purely from sales, but ultimately the work that they produce must be consumable. To members of OPS, an artist must begin by approaching experiences in a creative way and must devote the majority of time to reflect that creative approach through work. This definition maintains the seriousness of doing art without attaching monetary determining factors. Members explain what being an artist is about,

"First and foremost, just you have to make stuff. ... I... think it has to do with the kind of thinker that you are ... and the way that you are able to... make something come to life and the way that you problem solve... someone that can see something for something different than it ... the willingness to go deeper and see things in a creative way." [Artist 3]

"For me practically what it means is that I choose to designate a lot of time to making art instead of doing other things, but spiritually, socially, there are all sorts of implications that, it's too much to say." [Artist 2]

"It means taking time, focusing your energy on thinking about trying to understand reality and making things as a way of modeling that understanding so that you can look at it and consider it and then keep going with it." [Artist 1]

\section{Elements of the Underground Art World}

These four values, that success hinges on making and showing as much art as possible, that freedom of expression is more important than developing reputation, that professionalism is irrelevant and is substituted by seriousness, and that an artist is a person committing time to expression, all support the concept of art for art sake. This is important, because the established art world focuses on the concept of art for sale. 
The concept of art for art sake stands as the organizing principle for the underground art world system in which OPS participates. This system does not provide financial support for being an artist, but it does provide a way to show art to interested people. The support provided in the underground art world also moves beyond the realm of artistic support into the realm of social support. This world consists mostly of other artists, and is a source of feedback, celebration of the arts, and cultural creation. Before delving into these forms of support, I will explain what the venues in OPS' underground art world are. This world consists of different kinds of venues than the established world including DIY galleries and residencies, house shows, alternative galleries or spaces including bars, and the Internet. These venues provide the setting for interaction with the underground art world for OPS.

DIY Galleries

DIY galleries and residencies are spaces in people's homes that are converted into gallery space. Usually a DIY gallery is in a garage that has been renovated for showing artwork. These galleries usually host their visiting artists providing them a place to sleep, eat, and show work. They are curated by the people who live there, and are run on very little money that is either out of pocket or collected in small scale fundraisers.

\section{House Shows}

House shows are one night events, resembling a party. They usually host several bands or artists. A successful show draws a crowd of a hundred people or more. House shows are hosted by anyone who is willing and has a space that allows for a crowd and noise, usually a basement. They are very informal, and occur without consistency, at different times and location. They are free and make no profit. 


\section{Alternative Galleries}

Alternative gallery spaces and bars are also a part of this world, although they sometimes trend toward Becker's commercial model. These are spaces that are still for profit, but do not have the established reputation that established galleries strive for. These can be galleries, coffee houses, shops with merchandise, etc. They are also at bars that provide a quality sound system and large space for an audience, which allows for installations and music performances. All of these venues provide a space open to a larger number of artists outside galleries.

\section{Internet}

The Internet is a major part of the underground art world and affirms the value of art for art sake. It provides ways of showing art that are free an accessible to anyone at any time. It breaks the boundaries of time and space that characterize the gallery system. In fact, OPS makes some video art that is released only on the Internet. This allows OPS to represent themselves, rather than relying on a gallery for publicity, with a portfolio that is the entirety of their work.

The Internet is also a source of critique and review as art websites allow users to make comments on reviews posted for shows. It allows anyone to provide feedback and also shows interest in work by often showing the number of hits on any given page. It displaces the role that critics carry in the established world since critique is moved into a participatory public sphere,

"Critique is way more democratic now because of the Internet, anyone can be a critic, truly, although they always said everyone was a critic, but now a lot of reviews happen online, by people who just want to." [Artist 2] 
Additionally, the Internet is a source of strong connectedness in the underground world as it provides a platform for immediate knowledge about underground events since websites and social networking sites allow artists to advertise their events to a large audience. A member explains,

"[the underground scene] sort of has a mind of its own and...Now it's not necessarily one thing, like one new hip thing, it's like there is huge giant and I guess I just have to say that it's probably just because of the Internet. Everyone is just so, the information is just so everywhere, that it's not just little teeny underground bubbles, it big underground bubbles so there are just these big different scenes you know?" [Artist 3]

\section{The Underground Art World: Art for Art's Sake}

These venues create circumstances perpetuating the ideology of art for art sake. With roots in DIY culture, and also in art school culture, this is a system based on social ties, localized DIY culture, emerging spaces to show art, and low to no monetary value attached to art which ultimately organizes around cooperative social behavior.

\section{Origins of the Underground Art Culture}

An important factor in explaining underground culture is the influence of art schools. Many artists in the Portland area are graduates of art schools or art programs. These are places where cooperative behavior develops naturally, as artists find themselves in a group of peers often for the first time, bound by similar deadlines and financial barriers. In art school, people learn enthusiasm for other's work, and find support from their peers through their mutual investment in art. Furthermore, artists in school often find themselves working in community with one another as the nature of their work makes socializing and working possible at the same time. It is not unusual for 
a group of art student to get together to do homework, watch a movie, and drink beer at the same time, and this informal social work atmosphere forms a cultural norm for the underground as well. It also teaches artists to share with one another, anything from opinions to red paint. An OPS member recalls forming communities of like-minded people in art school,

"it happened more later in school when we had studios all in the same building... and you are put together in this sort of like beehive of little studios and everyone is like drinking beer like late at night and everyone is like totally tired and... it's also a really strong community in art school... [With OPS it is the same but] ... it's just kind of more of a micro scale. It's like i feel like we are this little bubble that's floating around all together instead of this wave" [Artist 3]

An OPS member recalled that many of her friends in the neighborhood went to art school, although not necessarily at the same time as she did. This root of underground culture is important because it shows that cooperative culture is grown in artist circles as an almost hidden curriculum component of school. That is, while the program of an art school might be preparing artists to enter into the gallery system, the design of the way that work gets done grows cooperation and community. In the established art world, this cooperative ethic is challenged as competitive economic forces change the relationship artists have with each other after school. However, the same cooperative culture can continue to exist in the underground and shows itself in peer support and shared cultural enthusiasm for art.

\section{The Underground Art World is Local}

OPS members live in Northeast Portland, a neighborhood with a high concentration of artists, and plenty of cheap housing that gives space to work. The neighborhood itself is fairly small, but home to many coffee shops, galleries, record 
stores, and boutiques. This setting is the stage for the underground art world in Portland, as it provides networks and resources for artists in close proximity.

The underground art system is anchored in the social ties of school friends and neighborhood. These social ties revolve around artistic pursuits, one member explains, 'We are definitely totally embedded in the social network that we are in. I mean, all of our friends are constantly producing creatively all the time and finding ways to show other people what they are doing, in whatever way that there is, so we are just part of that." [Artist 1]

These social ties are with other artists in the area, making this system local, and based in neighborhood rather than the more nationally or internationally oriented established system. Northeast Portland is the neighborhood that OPS' art world is located in, and it is home to many other artists who participate in this underground art world. One member explains,

"My life happens in north Portland, the majority of it, and it's a nice hang. I love living in an area too where you constantly run into people that you know and just see people. You have the music community and art community, its cool."[Artist 5]

Neighborhood keeps the culture of the underground in the hands of the artists since they live, work, show, and party there. In contrast to Becker's model that requires professional standards set by collectors and purchasers of art, a neighborhood setting allows artists to create their own culture. This culture is inherently decentralized and operates outside of established art world culture,

"We are really based in whatever you'd want to call it, punk or DIY culture, so that has always been separate anyway, and the Internet just makes it more functional" [Artist 2] 
The neighborhood of Northeast Portland also directly contributes to the ability for the underground art world to function well, as it provides cheap housing options and high concentrations of creative people who make peers, collaborators, and an audience,

"I can afford to live and make art here and not worry about working 5 days a week and I think there is something just about the kind of people here... it is a very comfortable place, which some people could argue is not conducive to people... really busting their balls or whatever making art but i think that actually it's just because there are so many people here that are doing that right now, everyone is like, 'that's exciting', and want to do [art]. So there is really a positive attitude about making art here and about seeing art." [Artist 3]

"A lot of our friends live there so its easy access, people are always stopping by our house, and we see friends at the coffee shop and house shows down the street." [Artist 1]

Here, a member contrasts the east side of Portland with the Pearl, which is in the Northwest and home to the established art world. The Pearl, although it provides access to high end galleries and funding, cannot support the needs of artists without the income to pay for a high end loft. She shows that neighborhood is a key factor in maintaining community with other artists, and with keeping costs low enough to do work,

"The east side is where most of my friends live and make art... I think it's a little cheaper here, it's changing all the time because some streets are getting developed but the east, the whole east in general is further away from downtown so... it's sort of like our own world over here...The Pearl is expensive, everywhere in northwest is expensive. It's cheap here, it's residential, there is more space and more opportunity, and houses, people live together a lot so they can do the group housing thing..." [Artist 3]

One important note about neighborhood is that while the underground provides connectedness between artists in the area, there is a lack of connectedness with original residents of the neighborhood. Original residents often cite that their culture is very separate from the art culture (Shaw and Sullivan, 2011). This division can be explained 
using Putman's concept of bridging and bonding social capital (2000). While artists in the neighborhood make strong connections among their peers and like-minded neighbors (bonding social capital), they lack a connection to other groups of people living in the area (bridging social capital).

\section{The Underground Art World is Constantly Emerging}

Additionally, this system is based on emerging places to show art, rather than reputation based hierarchical organization of venues. Essentially, because there is no monetary ingredient in the venues but rather hard work that comes with hosting large groups of people to what is usually a house or garage space, the venues in this world often change from location to location. This enables more people to participate in the showing of art work with easier entry into the art world. This entry can be self-directed rather than reliant on the authority of the gallery curators to show work. One member explained how entry into the underground art world can happen,

"How do you even break into [the established] world? $i$ think that's one thing that discourages people from even trying do art in the first place, they are like 'well $i$ can't get a show, even if $i$ make a bunch of work $i$ won't be able to get an art show', and [the underground] world is like the antidote to that. All you have to do is have an art show, hang your paintings in your living room and invite all your friends over, and then you have an art show. Then if you do that enough...it stops being just your friends that are aware of it and people that you don't know are aware of it, then you keep doing that for a while, then before you know it, hey you are an artist now, and it's really not that difficult." [Artist 4]

Because the underground art world places emphasis on the act of showing art, rather than its long term worth or durability, this creates more possibility for using supplies that are less costly and often means reusing old supplies or using found supplies. Where art for sale must be a product that carries long-term worth to its potential 
purchaser, which means using mediums that last for a long period of time such as

professional grade supplies, underground art projects are not usually for sale, so there is no need for this durability,

"we use mostly salvaged materials, TONS of free stuff, i mean, free stuff on the street in Portland is just, we have found so many cool things that we have mutated as far as installations go. Costumes, same thing, we made them ourselves" [Artist $5]$

The low cost of supplies is especially important to members of OPS, as they generally expect no profit from art projects. Also, since most work that OPS produces is not salable, they are able to reuse and reinvent parts of old projects to make their new projects, like costumes and wood. Again, this standard reflects the non-monetary nature of the system, money does not present a barrier to success since it hinges on doing quality work for a good audience. When OPS does make money, it is generally in small sales of merchandise and from donations, but most projects are self-funded,

"We've always operated at a deficit. Yeah, at loss, all loss of course... but we just pitch in, and pay for things, we have gotten some money from the community, Disjecta helped up raise money after we got back from the Tate, we sell things, when we were in the biennial we had merchandise type things, we make t-shirts, recordings, and things like that. We generate chunks of money, and we are very thrifty and we tend to really stretch our money" [Artist 5]

"We usually lose money [on projects], or always lose money, or sometimes we break even." [Artist 1]

"We are pretty much exclusively self-funded. We did receive like $\$ 200$ to do our installation at the Templeton building [ large warehouse space which hosted a large group show] which obviously was not enough money to do it but...there is 5 of us, so we absorb costs that way, and we received no money to go to England, but there was actually a bit of a fundraiser for us via Disjecta, just out of kindness" [Artist 2] 
On the surface, larger participation signals successful showing opportunities, since the audience available to see art work is larger. But the benefits of increased participation in the underground system also go beyond audience size, the system works more smoothly the more people there are available to both offer art work and space or showing it. Here members explain how their art world runs better with more cooperation,

"With house shows, it's a cooperative sort of thing. We do house shows here sometimes and on one level... we almost don't like it or it's a big pain in the ass because you know, you have to clean the house, and it gets trashed, and then you have to clean it again and people might fuck up your nice stuff...You have to devote two days to just 'we are doing this show here'... but at the same time we do it semi regularly because we almost feel like we owe it to the community to do it because we can do it. Our basement is a good space to see performances and if we don't do it, who is going to do it? The more houses that can do it the more that network thrives, and so it's like we have to do it because we want to keep that system happening. it's not like, 'oh we want to be the best house for house shows' which is kind of like how a business venue works, where it's like, 'ideally we would be the only music venue in town because then we would have a monopoly on all the bands' but you don't want to have your house be like the only house show place because it would [be trashed all the time]!" [Artist 4]

"Our friends have a space called Appendix, and they asked us to do a show there and we did and it was a really good experience for us and we did all of our work and showed it there and it was just people supporting each other's attempts to manifest reality- they get to have their reality of being a culturally significant DIY gallery in their house, and they try really hard and do a really good job, and we get to manifest our reality of making that installation and doing a performance in there." [Artist 2]

This world is about the benefits of sharing and working together, and not about rewards of reputation and high income.

Participation in the Underground is About Being Part of a Cultural Conversation

Cooperative behavior is the mode of participation in the underground art world, and the catalyst for the ultimate benefit offered by this system. Members of OPS emphasize that the underground art world is primarily concerned with the creation of 
culture and with the constant feedback provided by other participants for the work that they show. This creates conditions for more experimental art work and the highest degree of artistic freedom,

"I think the DIY scene is more open and trying lots of different new things all the time, and so it's like they are kind of creating the wave" [Artist 3]

"When you do something in your community, you keep seeing those people again and not only do you get feedback for months about it, ...it creates... a ripple; everyone is always influencing each other in the community. Whereas if we were to show at a commercial gallery it could be an equally meaningful experience, potentially, because I always think it's really amazing when someone comes up and loves your art that you wouldn't necessarily expect to and they...talk to you about it and it's really interesting to see who clicks with that, but then it's over and you did it and there is a lot of buildup and you don't really know what the effect was. I think it's because that is not in my community... but [in my community] there is immediate feedback from the community. So it's just a separate experience [in the established art world] - you did it and it's done, and in [the underground art world] it just keeps going and processing." [Artist 3]

"I really think that we are trying to make culture, we are just making... we are producers...self-generating, definitely very independent. And I think that that informs other parts of the whole thing, you know? The whole system." [Artist 3]

The underground world is a tight community that gives OPS members a connectedness to their peers that feed their work. Participation in the underground world does not just come with the presentation of their own work, but also in seeing other people's work and interacting with the people how made it. This contributes to a vibrant culture those OPS members explain is vital to their artistic production,

"I really love just being a part of a cultural conversation and that is the payoff for me... I don't know that I would want to lose that or get to a place where all I ever do is my art and I don't even go and see other shows and I'm just in my studio by myself all the time doing my thing which is...one thing that I associate with professional art... Rather than being a part of a cultural conversation with a peer group you just do your art all day long and don't have time to go see other people's art. And... I have seen people do that when they... get successful. When they achieve a certain amount of success, you stop seeing them at shows and stuff because all they are ever doing is working on their art or touring or going to do 
their art in other places and I think that's a problem. If I were to ever get more successful or whatever, I think I would really want to try to make sure that I stay grounded in a community of artists. Cause otherwise where are you going to get your ideas from?" [Artist 4]

"[wanting to play at house shows is] just an eternal thing, you know? You want to do interesting stuff. Its intimate, they are cool spaces, they are available for free and often they have the best energy. From my experience, and I have had vast experience with house shows over many years, they are just a life blood of local type scenes, especially smaller city or mid-cities type punk scenes and experimental scenes, ...that's where all the interesting music usually happens and they are often just the best shows ever." [Artist 5]

Thus, while the social support for artistic production comes from group work, the creative energy that inspires work is derived from the larger community. Participation in the community is a major factor in the continued production and sharing of art.

\section{The Underground Art World and the Network Effect}

The underground art world does not resemble the same closed circle system illustrated in chapter three. Rather, it resembles a growing network of interconnected circles of cooperation, see figure 2

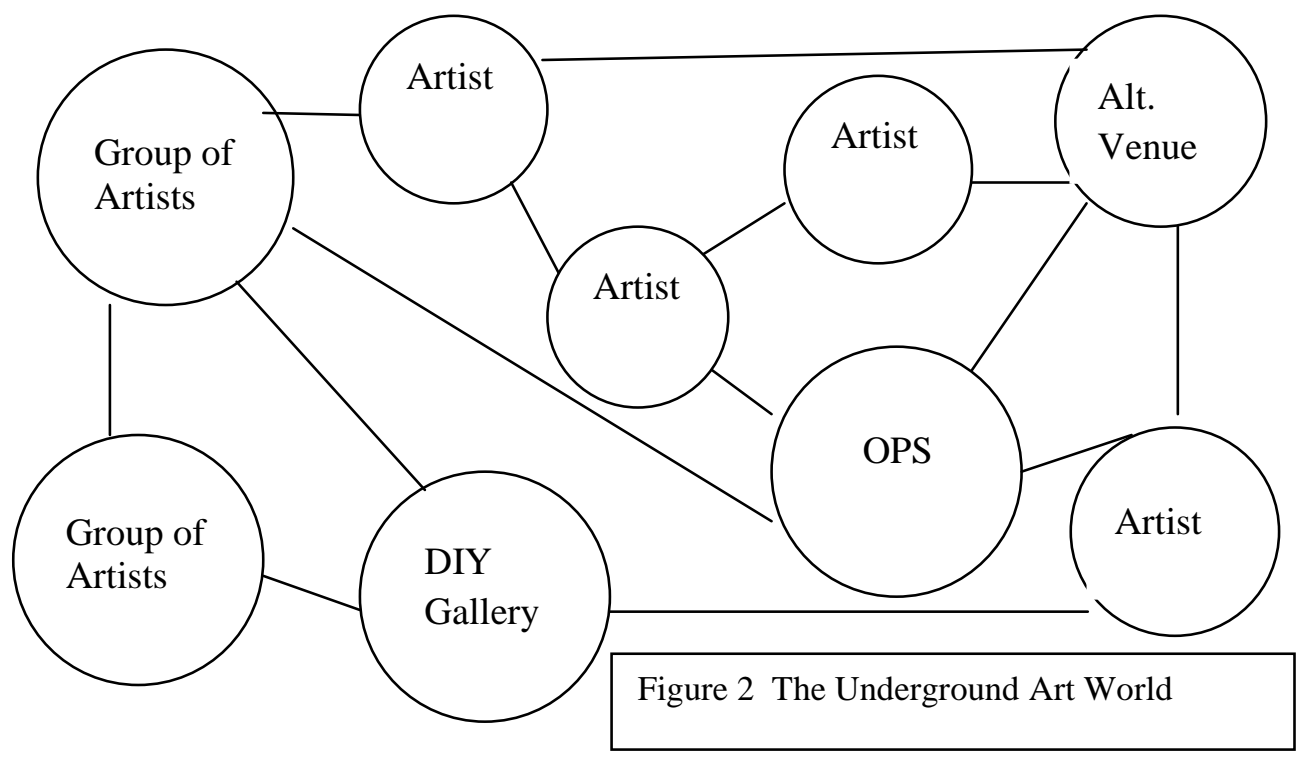


OPS is a small circle of cooperation. Most members pay rent together in addition to making art together. However, their cooperation also extends to other artists, especially in their neighborhood. These looser connections of cooperation make the social cohesion of the underground art world. Each small circle of cooperation has individuals who have connections to others. The more connections each person has, the more connections each group has. These connections form an audience when showing work, and often link to places to show it. This is a departure from the established world especially because it functions more smoothly the more people are involved in it. This is called a network effect, and has been explored by Uzzi in an ethnographic account of New York fashion designers. He finds that interconnectedness among fashion firms increases their success rates. However, designers are bound by a need for profit, and so their networks reach a limit, when too much sharing decreases profits. (Uzzi, 1996) The underground world is not limited however, because their networks do not function to increase profit, but to increase showing opportunities.

\section{Conclusion}

The values that make the ideology of the underground art world are focused around the idea of making art for the sake of art, in contrast to Becker's model which revolves around making art for sale. Instead, OPS articulated that success means showing art as much as possible to an interested audience, that artistic opportunity is more important than reputation when deciding where to show work, that professionalism is less 
important than seriousness and devoted time, and that ultimately being an artist means that you devote the majority of your time to expression. These are concepts do not require validation from any income related source, and so they form a separate meaning about the work that they do. The structure of the underground art world resembles a network system where increased participation makes the network stronger.

Taking cues from culture grown in art school where artists share mutual goals of getting homework done on a student budget, instead the underground art world revolves around neighborhood art community. This is a system that is comprised of artists working to support artists... The venues in the underground art world reduce costs for artists without devaluing the work that they do. What is most remarkable about this system is that it defies Becker's theory by enabling cooperative behavior and ideology. In fact, it actually depends on an inclusive structure to sustain itself. This inclusion ultimately creates culture on a local level that is easily accessible to artists who live in the area. 


\section{Chapter 7: FINDINGS PART 3, THE ESTABLISHED ART WORLD}

\section{Introduction}

OPS' also interacts with the established art world as well. The established world includes school galleries, museums, and commercial galleries. All of these are ultimately organized around the ideology of art for sale in contrast to the underground ideology of art for art sake. For school galleries, sale means maintaining a reputation for cutting edge art to attract students who will pay tuition. For museums, monetary value comes in the form of memberships, entrance fees, gift shop items and rental of spaces. For commercial galleries monetary gain comes through sale of work. Thus, the art featured there must attract an audience large enough to maintain the museum or it must be endowed for an initial large sum of money.

I explored OPS' relationship with the established art world to understand how the underground world connects to the established art world. My findings showed that the underground and the established art worlds bleed into one another. I include interviews with venues where OPS has shown to illustrate this continuum. These interviews are important for understanding the connection between artists and the places they show and the cultural divide between the underground and the established art world.

\section{OPS in the Established Art World}

These established interactions give OPS a new audience outside of their peer group, and an opportunity to show in spaces that are more public. However, while the established world has provided OPS with more visibility, the interactions that OPS describes with this world are often characterized by struggle and problems integrating 
their collective structure into a rigid system. Ultimately, this system is counter-intuitive to the underground system and is more difficult to access as an artist.

\section{Public Audience}

One of OPS's priorities is to reach a large audience. A benefit to showing art in the established art world is that the audience is public, meaning that their connection to the artists showing work is likely impersonal. Audiences in the established art world may attend a show because they read about it in a newspaper or magazine, or because the reputation of the venue draws them. Public audiences are important to OPS, as the audience that fuels the underground world tends to be homogenous since most people in the audience are also young artists. In the established world, OPS interfaces with an audience that is less integrated into their DIY culture. These channels are more easily accessible and visible and are usually promoted by the owners of the venues rather than the artists. Institutional promotion reaches a different audience than self-representation in the underground world does. Members explain the value of a diverse audience,

"I really like...when you feel like a crowd has an understanding of your past work, and ones where the crowd doesn't have any understanding or context for your work, those are my two favorite kinds." [Artist 5]

"If we were to show at a commercial gallery it could be an equally meaningful experience [as showing in the underground art world] potentially, because $i$ always think it's like really amazing when someone comes up and loves your art that you wouldn't necessarily expect to and they like just talk to you about it and it's like really interesting to see who clicks with that, but then it's over and you did it and there is a lot of buildup and you don't really know what the effect was." [Artist 3]

\section{OPS as Outsiders to the Established Art World}

The preceding quote begins to explain that while the audience offered by the established world is stimulating because it is different than the audience of the 
underground, the experience of showing in the established world is less interactive, as it does not provide the loop of feedback that the underground world does. Interactions with the established world are event based, not characterized by the routine access to the underground art world. They occur when there is a show rather than being part of a daily environment, and participation in the established art world depends on invitation from authority. This makes the structure of the system more foreign and harder to navigate, and OPS describes struggles to access the system and its resources,

“[everyone was saying], 'You guys gotta start doing grants.' but, if we start on a project, then we are doing it. Sometimes we ...get in the hole or whatever, but waiting for a grant, i don't know, it's just such an unsure thing... and we will keep doing it in the future, but... it is sort of hard to know how you fit into that grant because we are a group not an individual and there are a lot of complications about that... This grant was only categorized into individuals and organizations but we are not an organization, we are sort of like an individual made up of 5 lives so it was hard to know exactly where we fit in. And the organizations had to be a nonprofit organizations and we don't make profit but we are not technically a nonprofit so it's been hard to figure out where we fit into certain sort of stereotypes or whatever, categories." [Artist 3]

Furthermore, some interactions with the established system restrict artistic freedom and carry hints of exploitation. The relationship between people in the established world is characterized by monetary exchange, meaning formal business relationships between the artists and the venues.

One OPS member used their show at the Tate Modern in London to explain how the established Art Worlds is a profit making business. They had been provided with an opportunity to show their work at one of the most prestigious museums in the world, but they were not compensated for their work or their travel expenses while the Tate Modern profited from their presence. One member explains, 
"It's hard to tell what the motives are of these institutions sometimes ...we ran into that a lot when we did the thing at the Tate ... a lot of the artists' work was about ...maintain[ing] autonomy while working with a large institution... and for us it was a just kind of like, 'oh cool, like 90000 people are going to see our thing? we are not going to change our thing because it's at the Tate', but I could really see the skepticism over there that the artists felt toward the Tate because they felt like, 'well what are your motives?' and honestly a lot of them had some good points about it because it was a free festival but the Tate was making tons of money off selling concessions and people buying memberships but they didn't give any of the artists any money at all, and so there is sort of this asymmetry there where ... it's easy for [institutions] to take advantage of [artists] and be like 'well we are giving you an opportunity but we are also going to kind of take advantage of you while doing that by like not paying you but profiting from you.' You know?" [Artist 4]

Additionally, the members do not perceive the established world as part of the cultural creation occurring in the underground world.

In Portland, the established art world, especially the Portland art museum, tends to showcase more classic art than the contemporary artwork that OPS makes. This is problematic because the established world runs on credentialed hierarchical opinions on what makes for good art. Those opinions control resources, and so OPS members have a hard time gaining access to money and visibility that could be offered by the Portland established world,

"I think that the Portland art museum ... [has] got a real strong lock on their doors as far as what kind of art comes in. But it's not necessarily always what is cool and hip, it's like a conservative idea of what fine art is....our art museum is not very, i mean even now it's like not that much contemporary art flows through, and if there is a show it lasts for like three months because it is making money and so there is not a very rapid movement of upcoming stuff." [Artist 3]

One member gave her explanation of being turned down for a show at the Portland art

museum that OPS had been nominated to compete for,

"I just think a lot of people do take OPS really seriously because they know we produce a lot and we are enthusiastic human beings and you know we have a really very cohesive kind of world and visual aesthetic, but $i$ think the 
curators [at the Portland art museum] haven't gotten to the point where they fully respect us yet or something. I think maybe they think our work is scrappy, because a lot of the things that she chose were paintings, and the artists live in the country side and work a million hours every day on these paintings and lot of them were in their 30 s and 40 s and there were some 60 year old artists and kind of an older crowd. That's not to say that our group is all a young crowd, but it just seemed like they were looking for like this idea of maturity in art or something like that and I maybe some people just don't

see that in us yet, i guess, and they ... just don't take it seriously or something. You know, people get really really hooked on these ideas of what is good and what is important and what is accepted by other people of their rank." [Artist 3]

OPS's cultural values are not directed toward building reputation to out rank other artists, but to cooperate with them.

\section{Art for Sale vs. Art for Art Sake, the Underground and Established Art Worlds Compared}

The main difference between the two art worlds is that of competition versus cooperation. Driven by separate ideologies, art for monetary gain versus art for art sake, the two worlds work contrary to one another. Because of the monetary component in the established world, there is competition for available resources. In the underground world, cooperative behavior creates more resources. One member explains the role of competition and cooperation in her interactions with the OPS's art world,

"Mostly we focus on cooperating with other groups because we like that kind of thing, and it has been awesome to collaborate with other groups, with Wooly Mammoth and Smegma, it's the closest thing ever to have your own group merge with another group... I would say the only time we are competitive with other groups is like we have applied for grants and stuff like that so it was like obviously we had to compete with other groups with that sort of thing, but as far as showing or having our stuff out there or something, I don't feel competition about that" [Artist 1]

Here, one member explains the origins of competition in his interactions with the

established art world, 
"I think that there is inevitable competition, I wish that there wasn't but it is just a product of capitalism and absence of utopia... That's not what drives our work, but like, we applied for a grant, other people also applied for the grant, we didn't get the grant, we don't get to do that project or have that money." [Artist 2]

\section{Cooperation and Competition Make Different Art Worlds}

Table 1 compares the established and underground art worlds. The established art world forces artists into competition with one another while the underground thrives on cooperative resources. The established world is based on hierarchical organization, meaning that some venues and critics carry more important weight than others. This is a result of established outlets for art, and the reputation of those establishments to be authorities on what quality work is. Conversely, the underground art world is decentralized, with no standing authority about what good art is. Rather, it is based in emerging places to show art which constantly change. Reputations for underground venues come from the audience and the reputations of the artists who are showing work rather than the location.

The audience included in each of these worlds reinforces this contrast. The established world's audience includes the public, people who consume but do not produce art. They gain access and exposure to art through more easily accessible channels, such as reviews in newspapers and promotion from venues that have money for distribution to the public and an established presence in the city. The underground does not have this visibility, and its audience is fueled mostly by peers. These non-monetary outlets for art do not have the resources for promotion, and rely on word of mouth and Internet self-representation for attracting an audience. While this is effective, the promotion 


\begin{tabular}{|l|l|l|}
\hline & $\begin{array}{l}\text { Established Art } \\
\text { World: } \\
\text { Art For Sale }\end{array}$ & $\begin{array}{l}\text { Underground Art } \\
\text { World: Art for Art } \\
\text { Sake }\end{array}$ \\
\hline Organization & Hierarchical & Flat and Decentralized \\
\hline Audience & Public & Peers \\
\hline \# of Participating \\
Artists & Few & Many \\
\hline Revenue & Sale of Art & $\begin{array}{l}\text { Part-time work and } \\
\text { small art earnings }\end{array}$ \\
\hline $\begin{array}{l}\text { Kind of Relationship } \\
\text { Between Art makers } \\
\text { and Art showers }\end{array}$ & Business & Social \\
\hline Kind of Supplies & Professional, High & Found, re-used \\
\hline Cultural Orientation & National/International & Local/Regional \\
\hline $\begin{array}{l}\text { Is Portland a good } \\
\text { place to do art? }\end{array}$ & No & Yes \\
\hline
\end{tabular}

Table 1 Two Art Worlds Compared

generally only reaches people that are already included in the social circle of the artists who are showing work. In addition to the character of the audience, the access of artists to each world is different.

While the underground is host to many artists working together, the established world gives space to a few selected artists out of many. This access is restricted by competition for available resources that comes with the flow of money. The monetary versus non-monetary nature of both worlds also changes the relationship that artists have to other participants as well. While the established world is characterized by business oriented zero-sum relationships, the underground is characterized by social relationships 
and mutual goals. For example, where showing in the underground typically happens because a friend knows of your art and wants to host you, showing in the established world takes a formal request either from the artist or the institution, and often requires professional applications to show work like a portfolio and artist statement before a show is chosen.

These professional standards are also carried into the expectations for art work that is shown in the established art world. Art for sale drives this standard, as art work is sold for high prices to elite patrons. Sold art is meant to become part of a permanent collection, as its monetary value comes with time and reputation. Thus, the materials used to create work are expected to last. Professional grade art supplies are expensive, but expected for work that is meant to be sold at a high price. The value of these permanent collections is reinforced by museums and professional art appraisers. The underground world does not commit to any permanency in the art work shown there, since it carries no monetary value and is usually not even a salable product. This cuts costs for artists, since they can utilize found supplies and reuse old supplies.

Another stark contrast between the underground and the established is the cultural orientation of the artists and venues in each system. While the underground is a local city and neighborhood based culture, the established world is oriented towards the national and even international larger art world, some cities carrying better reputations, and thus more money, than others. This makes the culture of the world oriented always towards a more prestigious ranking that is decided by critics and elite patrons on a very large scale. Ultimately, this distinction is the deciding factor about whether or not Portland is a good place to do art. Portland is not a core art city, because the flow of money through 
established channels is low. The attention that Portland attracts from elite critics is also low, since there is not much money to fund contemporary projects and its press is regional rather than national.

On the other hand, the layout and culture of Portland contributes to a very healthy underground art world. For artists who are primarily concerned with sharing their art to a willing audience, the underground provides what they need. This contrast will be discussed in depth below.

\section{Showing Art in the Established and the Underground Art Worlds}

The established world and the underground world exist on a continuum- they are not dichotomous. This continuum blurs the lines between ideologies of both systems, and this can be seen easily by looking at the way that venues operate. Some venues operate for profit, while others are run at no cost and for no profit from people's homes, while some combine profit making and art for art sake, making just enough to pay rent and reach a public audience.

This continuum is the world where OPS shows their work. While they make their work in their local and underground social world, they show their work in a variety of locations. Although the majority of their work is shown in the underground, they have also shown in more established places. However members bring their underground values to the established world, showing work there without adopting the ideology of art for art sake. OPS approaches showing in the established world the same way that they do in the underground, not adopting the ideology of art for sale. Thus, the boundaries around being part of the underground world are loose rather than absolute. 
Members of OPS explained that rather than operating in one world or the other, maintaining a regular involvement in the underground in general is important. One member explained that some artists they knew gained easy entry into the established art world because their media were more easily received by commercial galleries, but their participation in their neighborhood art world was continued. Another member explained that often those whose work is well received by the established world are often too busy with individual work to come to other peoples shows, and that this was an unfortunate effect of integration into the commercial world. Maintaining connection to the underground and the ideology of the underground is what makes work rewarding artistically and socially, so involvement in the established world for OPS is not a transition away from the underground, but an additional outlet and audience for their work.

For members of OPS artistic freedom comes first. If a venue, underground or established, offers the right artistic opportunity the group shows there. Placing high priority on artistic freedom is the answer to the problem of selling out. The underground culture fosters a resistance to the established commercial world as it reorients values away from financial and reputation based prowess. While this is important to members of OPS, their choice in where to show is less political than it is artistic. As explained in the previous chapter, showing only in established channels would remove OPS from their cultural connectedness and in doing so separate them from inspiration and community. Thus, participation in the underground balances OPS's decisions about showing work rather than limiting their preference to one world or the other. This fluidity is important 
considering the blurry continuum that exists between the established and underground worlds.

Interviews with some of the people that run the venues where OPS has shown illuminated the continuum and explained the connection between these worlds. These findings verified the differences between the underground and the established art world, but with a sharper focus on the ways that the elements of an art world are part of a cultural value system. While the interview with the DIY gallery curator reflected the values of the underground, the alternative gallery owner expressed tendency towards the established world and focused on reputation while still employing more cooperative models for supporting her gallery. Finally, the interview with the school gallery coordinator and DIY gallery curator was a mixture of the established and the underground, operating in the underground system with a high degree of connectedness and awareness of the established credentialed art world.

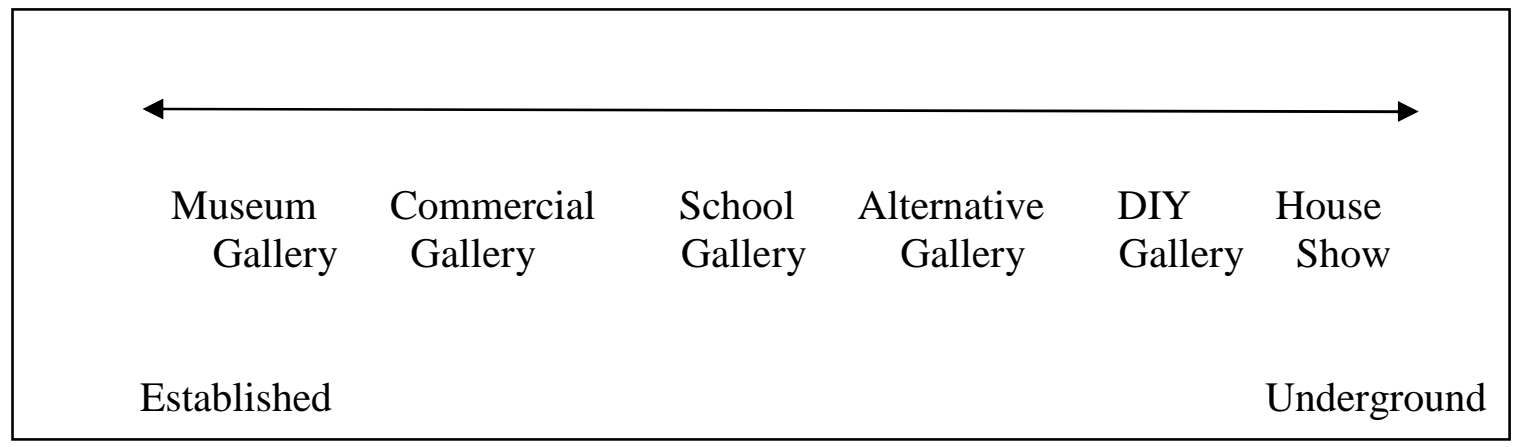

Figure 3 The Continuum Between the Established and Underground Art Worlds

Figure 3 shows venues where OPS has shown on this spectrum. Museums are the most established place that OPS has shown. Leading museums are established authorities on what constitutes good art nationally and internationally. They set the standards for the 
rest of the established art world and showing at top museums carries the highest prestige. Commercial galleries are similar, although slightly less permanent. Their reputations are more subject to change, and maintaining reputation through high quality shows that receive positive reviews from top critics is important. Alternative galleries often trend towards commercial gallery standards, but are less competitive and often employ some elements of the underground as they are less reliant on reviews since they do not have the reputation of an established gallery. Often, alternative galleries gain an audience through means other than the artwork itself. For example, a gallery in a coffee house gains an audience when people come there to drink coffee. This is necessary because sales outside of artwork maintain the ability for the space to be open to artists. The exposure they gain comes from public interest generated by people who see the artwork as a consequence of their other, unrelated purchases. School galleries are more cooperative. For most of the year, they feature student work that requires no competition. However, when OPS shows at a school gallery it is because they have been asked to show there based on their reputation. School galleries also mark an important departure from the high end the art world. Although some non-students might visit school galleries, the majority of the audience is young artists who are part of the program at the school. DIY galleries are more underground than school galleries as they operate independently of establishments. They also have an audience of peers. However, they are somewhat permanent, and thus carry some lasting reputation. House shows are the most underground and cooperative venue where OPS shows. They are inconstant locations carrying only the reputations of the artists who are participating in the show, which is seen only by peers who are in the social circle of the organizers or the participants. 


\section{Sustaining a Venue on the Continuum of the Established and Underground Art World}

Just as artists integrate themselves in the continuum between the established and the underground art world, so do venues. In order to understand how the people who show art sustain their venues I interviewed the owners of three venues where OPS has shown work. The first participant is an alternative gallery owner in East Portland. The second is a school gallery coordinator and DIY gallery curator/owner. The third interview is with a DIY gallery/residency that he co-curates with roommates.

Exploring how venue owners do their work an important element in understanding the functioning of the art world in Portland, because people who show work are also essential links in the artistic process. These interviews showed that the methods people employ for sustaining their venues align with either the underground or established art worlds, depending on their intended trajectory and ideology about why and how they show work. In other words, they structure their strategies to maintain their venues based on the values and methods of the art worlds that they participate in.

\section{Alternative Gallery}

The first interview shows how an alternative gallery with an intention to enter into the established art world sustains itself using a combination of social resources from the underground art world, and standards in the established art world. The alternative gallery is located in the near east side in Portland, and is a small store front for profit gallery with very limited space. It is host to a new artist every month, in addition to selling a variety of gift products including soap and records. I found that while her cultural orientation and goals were tend towards Becker's model, she still employed a cooperative model for 
raising money and still enjoyed the benefits of the shared skill network of the underground. This was important in illuminating the spectrum of established to underground by providing a portrait of how a gallery might begin to take root on its way to becoming part of the established world.

This is a gallery that organizes around the principle of art for sale, but works are sold for less money than more established galleries. Showing at this gallery is a step in the entry into the established system, meaning that artists who are featured here do not have the established reputations that a more prestigious gallery might have. However, because the owner is beginning to establish her reputation in Portland for finding artists, there is a higher likelihood that showing at this gallery will lead to more permanent entry into the established world. She is able to feature new artists and more experimental work since her overhead costs are low; she pays no employees and has lower rent as her gallery is not located in the most established art district in Northwest Portland, the Pearl District. This attracts a young audience of mostly other artists, although her audience is becoming more diverse. She offers artists a place to show with higher ranking than an entry level gallery. Here she explains,

"It's good because [my gallery] is starting to get a reputation that I have a really good eye to find people that are not well known yet... so it's a good start, it's kind of like the transition between showing in a coffee shop and being represented by a gallery in the Pearl. These people especially right now are not really taking on new artists, it's too much of a risk for them, I think their overhead is so huge, that they pay their people, they all have salaries, big rent, whatever, and so it's one alternative... It has a young audience that will come to openings, and we get a really good response from most of the shows so I guess that's good."

This gallery often sells to a younger, more peer audience that cannot afford the prices of work sold in the Pearl. However, while this clientele is younger, the owner assumes a 
more traditional approach to art collections as she describes the monetary value of the artwork,

"The clientele is very different, people are not very wealthy, every time people buy something you can tell it's very very meaningful to them, and a lot of the time they will do a payment plan even if it's just like 400 dollars. They are just more kind of our peers, they are a lot younger, they can see that they are making an investment that is not just I love this I need to have it... I think they can see that a lot of these people are going to fetch more money in a few years and they want to get it while it's still cheap you know, and they love it anyway. I feel a lot of people do it to be supportive, as opposed to just do it to get the piece”

The artwork on display during our interview was reflective of professional standards that are meant for long term collections. The show was a series of paintings made from professional grade supplies, including study mounted canvas and high quality paint.

Although her art sales are beginning to pick up, she still struggles to become a financially stable establishment and devotes the majority of her time to the gallery while juggling a part time job curating at Stumptown coffee, a local coffee shop with a gallery space. Just as OPS juggles part time work with their artistic careers, so does this gallery owner. Here she explains,

"At this point I have only done this for the love of it, the passion, I still have not gotten paid, I work like 40, 50, 60 hours a week so I think that does make it different from traditional galleries... even when its difficult it's just that difficult doesn't mean that you don't get paid ever, you know? You have employees; you have food for your openings. I think the means are just so different, this is all just scraping by and trying to not make it look like that, you know?"

This financial struggle is complicated by trying to keep up standards for what a single purpose gallery should be. While her merchandise sales help to keep the gallery afloat, her non-traditional model negatively affects her established reputation, which decreases her chances of being reviewed. This is problematic considering that reputation 
comes with these reviews, and so her gallery is sometimes ignored by the established world's critics,

"The fact that I am a store is also very different than most places because a lot of the art critics are still not taking it very seriously that we are a gallery because we are also a store..."

However, while the established world does not quite recognize her, she is able to gain support from friends and other volunteers who want to help the gallery. This help comes in the form of skill sharing, and from people who have time and skills to help. These are the same social resources that OPS needs from the underground to sustain making their work. In this case, social resources sustain the ability to show the work of others. These are less formal relationships and more cooperative than the business relationships in the established world,

"I'm really lucky that I get a lot of people to help, in terms of labor,... volunteers or design, I have someone that does my branding, and I have someone who is going to redo our website and make it more visual and more appealing... They always say the same things,... "I love [your gallery] and I want to help out and I would like to donate some of my time”, and I don't think that would happen to... a bigger gallery"

She also employs different models of fundraising. In order to help her venue make a transition into primarily a gallery space, she has designed a membership program that offers at least three free events and talks to members for six dollars a month. Priced from the cost of the Sunday New York Times, she offers a fun and affordable program that helps support the show,

"I feel that 6 dollars ... is a reasonable price that people can still afford once a month, and if I can get like 50 to a 100 members it will cover half my rent and I won't have to worry so much about the shop part, and I can focus more on the gallery and on the arts and performance readings... The people that have been members love being part of it, they love coming and they see the same people, a 
lot of the time, they like the events, they are totally fine with the fact that, you know they aren't going to come three times a month"

However, asking for money has been problematic especially for the younger audience that attends events to support their friends and peers. This is a good example of a difference between the underground and established art worlds. While she needs monetary flow to continue her business and to continue showcasing new artists, members of the underground art world are not able or receptive to having to pay to see their peers' work.

Promotion for work in her gallery reflects both the underground and the established art world. She utilizes the Internet to advertise events and openings, primarily through her website and her Facebook page. This reaches the social group that she is connected to, and reflects the methods of promotion that the underground uses. Local newspapers, such as the Oregonian and Portland Mercury also list her openings along with the established galleries. She also gets listed online on websites that act as platforms for Portland art like PORT and PDX ultra and gains some attention by representing one of the members of a nationally popular band. This combination of promotion reaches a wider audience than just the word of mouth that purely underground promotions do.

This gallery is making a transition into the established world as it is becoming more traditional about the way that shows are presented. The owner is changing the way that she hangs shows, by increasing her involvement in what can be shown and where work is hung. She is doing this to protect and increase the reputation of the gallery,

"I'm getting more and more picky with what I show and more controlling with what I let them show... Before I let people show things that I didn't like, and I let them convince me that it was the right thing to do and that piece needed to be in the show because it was so important, when my gut feeling was like this doesn't fit 
in,... i think it should get edited. Then in retrospect I sit here all the time and I'm like 'why wasn't I assertive?' because it turns out either... a review would confirm that... I was right or the way that the public will react to a show."

Additionally, she is developing a more official business relationship with the artists that she features rather than the informal relationships that she began with by beginning to officially represent artists and requiring her artists to sign contracts. However, while these relationships change, she emphasizes that she does not intend to change the experimental art that she shows,

"I want it to become definitely more and more of a gallery. I [am] being more controlling of shows and asking more from artists... The contract that I have is really strict, there is a timeline, I need more information from them... I need proposals, whereas before it was never like that. I would be like, 'do you wanna have a show?' 'yes.', 'cool'. Then I would see them the day before and they would show me the stuff and then it would go up...That can't happen like that anymore, just because my trust is just sometimes naive. So hopefully it will be a little bit more like a traditional gallery, but I am still going to be myself you know, I like the people I work with, I think we are all very non-traditional, very eccentric, very weird people and that is who I am interested in working with."

This also marks a transition into the established world, and an increasing exclusivity in her model. This model provides fewer showing opportunities to the pool of artists that might try to access her venue, making her gallery more competitive.

Ultimately, her cultural perspective is that of the established model, although the art she features is still more experimental. She seeks to access the established system through building her reputation, following the model of other commercial galleries through formal contracts, artist representation and editing of work. This cultural perspective is also reflected in her thoughts about whether or not Portland is a good place to show art, although the culture of Portland supports creative endeavors. Her opinion is that Portland is over-saturated with artwork, and that this contributes to a blander 
environment. This reflects the established art world which favors competitive showing that only features the few artists that are deemed promising. This stands in sharp contrast to the underground model which supports high numbers of people making art and favors a competitive model that showcases fewer artists.

DIY Gallery

Contrast her with a well-known DIY gallery in Northeast Portland in the Alberta Arts district. This is a mostly performance and installation gallery in the garage of a group house that features three week exhibits and residencies for nine months out of the year, taking three months off in during the winter with Last Thursday, the monthly Alberta Art walk. There are four curators of the gallery, all of whom live at the house where it is located. Although they have high standards for presentation of work that might appear typical of the established art world, this gallery is almost completely representative of the underground art world. The intended trajectory for this venue is not to transition towards the established art world, but to maintain a strong presence in the underground art world. Their values and methods for doing their work affirm the concept of art for art sake.

The format for shows at this gallery is that the artists are able to stay at the house attached to the garage with all the co-curators who live there. During this time, the artists and the co-curators install and critique the show, and host an opening that coincides with the art walk on Alberta. The work shown in this gallery is usually not for sale, since it often features impermanent installations or performance based work. 
The gallery hosts a fundraiser once a year by raffling small donated works from the artists featured in the previous year, accompanied by a free music show. Funds raised contributed to installing lighting and a new wall in the garage, in addition to a small amount of money to define an outdoor performance space by lining it with hay bales for people to sit on.

This gallery is organized around the concept of art for art sake. Rather than a commercial model, this gallery is concerned with showcasing art for the community around them, and participating in the process of artistic creation. This gallery has no intention of moving toward an established model the way that the alternative gallery in the preceding section does. He explains,

"[We] were thinking a lot about urban spaces... in terms of what's the more efficient way to use the space and how do you bring that space to a larger community and that's kind of the model that we were running upon for the very early beginnings. As I said it's been really fluid...I guess we ask questions about is this right for appendix rather than is this going to make us more money or something. I mean we don't make any money, and it's not something to sell."

Their audience mostly consists of other artists, although they do benefit from the Last Thursday art walk since some public is able to find their space by proximity to the street festival. They also promote their openings via email, text messages, phone calls, and Facebook which reaches their mailing list and their friends. The co-curator explains, "Part of what makes [my gallery] interesting to me is that we have a community of artists in Portland who have known us and have gotten to know us through mostly word of mouth or Facebook or some sort of enterprising situation and then there are also the people who will see a fire down the alleyway, ... and a group of people standing and they will walk down and turn the corner and be in our space and they will start asking questions and sometimes they are quite drunk and they will give us first hand...exactly what they are thinking which is always really nice to have people respond." 
Also, this gallery places emphasis on the social and interactive element of work shown which reflects the more informal nature of relationships in the underground art world. This is a contrast to the established art world that is formal and event based. This gallery includes the artistic process in their model of showing work. He explains the process of the residency,

"We make ourselves pretty available to whoever is installing and we have conversations with the work... and that's part of what is fun about this thing for us."

"We host dinners with the artists, we have them over for conversations. We are really evaluating the work a lot. We do critiques a lot of the time and we're not asking for finished work, we are asking for work that will respond to their practice and push their practice forward and also give us something to talk about and think about and we try and stay really close in contact with whoever is working."

This feedback model provides benefits for the artists who show at the gallery, but also to the co-curators. In fact, the co-curator I interviewed moved to Portland just to be part of this interactive community model from New Jersey. This reflects the cooperative nature of the underground, where both the gallery and the artist gain creative benefits from working with each other instead of competing,

"You are always around, and so a lot of the time someone will be fussing with something that they are thinking about in their room and you will go and just talk about it for a good long period of time. Also i think living together and eating together and working together, those three things are really important in terms of forming a relationship with someone and being able to trust someone to look at your work, respond to your work, and know that they are both smart people and truthful people. I think that's really intrinsically important to forming any type of artistic or any community. I mean that's why people live together, that's why I came out here-I was living in the living room for a while with a sheet across it, and it wasn't really a real living space."

Importantly, the informal interactive nature of their method does not compromise the seriousness with which they approach showing work. In fact, their openings are listed 
in the Portland Mercury, a local independent newspaper with city wide distribution. He explains what the gallery offers to their artists,

"[My gallery gives artists] space to show a lot of the time, visibility in Portland. We have garnered a lot of ... respect for the quality that we are putting forth but also the fact that we are really into it. We are not joking, we are serious but we are also open and willing to talk and so we have people come in who maybe have had interactions with Portland artists that will have a different interaction here. We offer them four people who are thinking who want to talk about it. We also offer dinner."

The cultural orientation of this gallery is local and DIY. The concern of the gallery is to provide a showcase of excellent art work that reaches the local audience that lives in or visits the neighborhood. This co-curator favors the art scene in Portland for its openness and flexibility,

"If you do a project well,...and you are honest, and you have a lot of work ethic, and you want to make whatever it is happen, whether it's your practice or the space that you are running, whether it's just forming a community, then people will see that and respond to it because unlike other cities, other people really do respond to someone who is working hard because it's a small community and its growing still and it's not closed, there's not a finite amount of space for people to work in."

"It's also very livable, Portland, that's just one of those things... so we all have day jobs and we don't make a ton of money but we have this great space that we can use in whatever way that we want to, whereas if I was living in another city I might be living in a small apartment or a small house and be worrying all the time and also not be able to find a space to do that kind of similar thing..."

DIY Gallery and School Gallery, a Foot in Each World

Finally, I conducted an interview with the owner/curator of another DIY gallery in Portland who is also the director of a Portland State University's art program's gallery spaces. This participant has a foot in both the underground art world and in the established art world. The work featured in his DIY gallery is experimental work that 
would not easily be received by the established art world in Portland, but his methods of promotion and his formal approach to showing work in the school gallery are intentionally participatory in the established art world culture. He favors competition to stimulate artistic production, while maintaining an experimental, not salable, artistic choice for shows that he organizes. His DIY gallery features contemporary experimental work, and he founded it because the established world in Portland did not offer that kind of venue,

"[The works I feature] are not unlike things you would see in institutions elsewhere... For me it was just showing things that were contemporary and also [showing] things that I was interested in that weren't here. If I was going to stay here I had to fill that gap for myself."

But there was also a social, more underground value component of founding his gallery,

"I came to Portland and I saw that there was no space... I'm not one of those people that can lock themselves away in the studio and make their work and show in a commercial gallery ... part of that for me is that I want to get those people that I was so used to working with... for 8 years in my room.”

Curating his gallery grants him artistic freedom to show the work that he finds most compelling, which stands in contrast to his day job,

“yeah, it's not a non-profit but it's a not-profit so I can do whatever I want to do, it's my name on the building so it's easy for me to say no to people whereas like a curatorial position like this or a director of a gallery... it's a lot different how you work"

"[My DIY gallery] is it's my name on the front, I pay for it, I don't have a board of directors, I don't have a boss, except. You know, the work... I'm a little more free to do what I want to do there, people can come and stay there, I have got room for them to stay there, so an entire latent dialogue gets created, which occasionally happens [at PSU]... but it's an institution so basically its first mandate is to serve the art students and the PSU community, and then to serve Portland in general and then to be part of that larger dialogue so a lot of my duty here is supporting the BFA students" 
As a representative of both, he acts as a communication between the two worlds, filtering artists from the underground into the established, and making the established world aware of the underground. This is done by curating a few shows in school galleries per year that are not student shows, but contemporary artists of his choosing. His role as a middle man is important to artists as he is able to introduce underground art work to the established world since he still participates in it. One OPS member explains the importance of these actors in the art world,

"In our experience I think every time we have done something that is more in the official world it's usually because there is some person in the middle." [Artist 4]

His connections to the underground art world help artists to trust the established world,

“if you feel like you've got sort of an honest broker, then you might be more willing to do something at a big institution, if you feel like, 'at least I know this guy is legit because I know him from the scene, then you might not be as skeptical." [Artist 4]

Although his DIY gallery features more experimental work, his cultural perspective is that of the established world as he favors weeding out non-remarkable artists through competition rather than enabling as many people to make art as possible. He explains,

"I argue that the critical dialogue here isn't real critical, its real touchy feel-y. I would honestly say there is not enough critical feedback but people argue that that's not healthy and the trend now is that that's not healthy and everything should be allowed to happen and other things will rise to the surface. I'm a little bit more... everyone goes to everyone's show and everyone tells them that it looks great, and in other towns that does exist, but also the money exists so it naturally washes out a certain level of things."

He also emphasizes that the standards of the established world are not upheld in Portland, and that this also contributes to a less noteworthy art scene,

'There isn't a lot of professionalism and just kind a lot of slacking off here" 
One interesting component of this participant's art world is that although his work is primarily not for sale, as the school gallery and his DIY gallery do not sell artwork, he still orients his thinking around the national or international established art world. His methods for promoting shows at both galleries are very formal. He explains,

"What I do differently at [my gallery] that others might not do with their alternative spaces, ... [is] everything that goes out into the world is ephemera. It's professionally done, it might occasionally be...off color or shocking to people but everything is well done... There is a press release that is well written, everything is in place for that dialogue, that established [art world] level."

Also, it is noteworthy that while he sets up this dialogue, he does not perceive his gallery as holding the cultural weight that the other DIY co-curator does. Rather, because his cultural orientation is national or international he considers the artists who show at his gallery either as helping him or as taking on the show for its increased artistic freedom,

"It's not going to advance their career in any way, they are not going to get a critical local attention here, part of me feels like, I think they do it out of, l think they like me, or they like what $i$ have shown, or they want to come to Portland... Artists are hungry to see what they want to do done, and I let them do what they want to do whereas there are even other 'underground' spaces where they do dictate... I mean I do within reason, I mean, no fire or water.”

His audience consists mostly of other artists, both in the DIY gallery and in the school gallery, although the established position of the university attracts a somewhat more public audience. While he finds the established world's resources scarce in Portland, he ultimately thinks that Portland is a good place to do art because the absence of those resources contributes to artistic freedom,

"I think [Portland is] a great place to do art,... I honestly think that artists should push it more here, no matter what their field is, no matter what their expression, $i$ think they are not pushing it out here cause you can do whatever you want here. The thing is, you can't guarantee that people are going to pay attention,...there is very little money here, all of the things that people don't like about the art world, like critical feedback, like the institution, like the money 


\section{Chapter 8: CONCLUSIONS}

\section{Working Together is a Key to Sustaining Artistic Production}

My first question, How do collectives help artists to sustain their artistic

practice? is answered during my observation phase. I find that group work supports Becker's idea that artistic production requires a social world. However, this research shows that the economic components that Becker uses to frame his ideas about social worlds are not the main contributors to the process of making art for the artists in OPS. Rather, the cooperative links that influence them most and shape the possibilities of art work are the people who support their artistic ventures, their peers. In order to sustain artistic output, artists need:

- The resources for making quality work: Time, Money, Ideas, Critique, and Places to Show

- The social support to make it worthwhile

Artist working in groups achieve these elements more easily. Artistic Support

My findings show that working in a group supports individual artist's ability to continue making their art. Having a consistently accessible group of peers at every stage of the artistic process from inspiration, to idea generation, to making work, and finally showing it, creates an environment that is stimulating. Especially in regards to critique, constant feedback makes every step of the artistic process more engaging and produces a better artistic outcome than individual work would. 
Furthermore, working in a group also aids artists in keeping up work even when their individual practice might be less active. Working in a group refreshes ideas and makes it easier to complete projects on time since it establishes a productive atmosphere and a way to participate in it. It also reduces financial burdens of projects and makes it possible to execute large projects cheaply and in a reasonable amount of time.

\section{Social Support}

Group work also provides a social network that supports artists. This network gives individual artists access to a larger audience for showing both group and individual work. Furthermore, it establishes a cooperative culture that supports making art. While established art worlds are competitive and can be difficult to access, a group of peers and a larger social network to support work tempers an otherwise discouraging dynamic.

\section{Portland's Underground is an Adaptable System that is Good for Artists}

My second question, How is Portland's underground art world structured and sustained? is answered by the interview phases of this research. Using Becker's concept of cooperative links, the underground art world shows itself as a different system from the commercial gallery work that he explores. It still has galleries, artists, and an audience, but these categories are more fluid and tend to be comprised of artists in every step of the way. Hierarchical gallery representation and critique are replaced by popular support of emerging locations and self-representation on the Internet. This is the environment of a creative ecology described by Shorthose and Strange. 
Ultimately, this research reveals Portland's underground art world as an adaptable, accessible system for artists because it runs on inclusion and can support a large number of artists. Portland's underground art world is a creative atmosphere devoid of most of the monetary influence present in established art worlds in other cities. This is due to both subcultural influence of DIY and cultural values and practices of sharing and cooperation likely learned in art school. The underground values surrounding the concept of art for art sake support artists and create the possibility to pursue an engagement in art even without an income from art. An artist in this world is defined as a person who is seriously committed to their practice through devoting time and energy to making and showing work rather than a professional resume of high end critique and gallery representation. This is a world of peer support and mutual investment in the arts. As such, it provides artists with more freedom, better feedback, influence on cultural in a local accessible way, and a cooperative and inclusive environment.

\section{More Freedom}

Without restriction of space in a gallery, expectations of long-lasting construction and supplies, or even producing a salable final product, the underground art world grants greater artistic freedom than the established. Overhead costs can be kept low as supplies can be reused from project to project, and the initial investment in a project can be kept low by incorporating found objects into work.

\section{Better Feedback}

Rather than waiting for professional reviews at the opening of a show, artists in the underground are able to access meaningful critique from their peers. Because the 
underground world is social, many people are able to support projects at every step of the way. This is a continuation of culture learned in art school, and produces stronger work.

\section{Local and Accessible}

The cultural orientation in the underground is local and accessible in contrast to the nationally hierarchical arrangement of the established world. This localization makes influence and entry into the world easier for artists since it favors emerging venues. Living in a creative neighborhood with cheap housing fosters an environment that helps artists do their work and a community that is an available audience for showing work.

\section{Cooperative and Inclusive}

The underground supports a large population of artists because it is not part of the competitive funnel of the established world. Instead, this system thrives on higher number of participants, since they provide new networks, venues, and artistic and cultural input for the underground art world. This is a model that can grow with an influx in population rather than become more exclusive. The main reason for this is the lack of monetary influence in the underground. Instead, art is made without an expectation for sale, and this opens more possibilities for showing experimental work and for using and reusing materials for making art since there is no expectation that the work will become part of a permanent collection. Thus, art making is more affordable and possible for a larger number of people than it would be in the established world.

\section{Portland's Power of Place}

My last question, How is the underground art world sustained by place? is answered by both observation and interview. First, Portland is an exemplary creative city, and attracts a population of people interested in the arts. The Pacific Northwest's DIY 
subculture structures Portland's underground art world by providing values that favor emergence and self-representation while its value diffusion to the larger Portland population supports the underground by providing an interested audience outside of the underground which consists mostly of peers.

Furthermore, the neighborhood structure particularly in the Northeast facilitates the underground because of its affordability and city amenities. It has large houses that can be rented out by a group of people, reducing cost of living. Houses in Portland often have basements as well, which provides studio space and the possibility of a venue for showing work or playing music, also reducing possible costs for artists. The neighborhood has a wealth of public transit options, and is also bike-able. Furthermore, the state of Oregon has an easily accessible food stamp program that has the ability to feed starving artists, and is widely used by the population. Additionally, the temperate climate is constantly cited as a major contributor to art culture in the Pacific Northwest, as it leaves a large amount of time during the year to sitting inside. This opens up time for practice and work on large projects for lack of better things to do in the rain. Thus, the layout and features of the city contribute to higher levels of community and lower costs of living.

Finally, the city's vicinity to core art cities is distant. This grants Portland the semi-peripheral insulation against economic depression/recession. Because there has never been a large amount of funding available for the arts, the art world in Portland does not rely on it the way that a core art city does. Its distance also grants it insulation from funneling talent into a core city close to Portland. Rather, the artists who are here 
continue to show in Portland and participate in the underground instead of moving to a nearby core city. This sustains the underground system by keeping active members.

\section{Reflections}

To add final context to my work, I return to three sub-questions I ask in the introduction. First, I asked, Are these artists satisfied with their work environment? The answer is yes. Members of OPS have an established work routine that accommodates their needs and allows them to support their art with part-time earnings while maintaining a healthy social life. They enjoy and choose to live in a neighborhood that fosters networks and culture.

Next, I wondered, Is the lifestyle of underground artists sustainable? While this research shows how the underground art system is sustained by easy involvement and growing participation, the ability for the underground world to sustain artists themselves is challenging. Especially for young artists without heavy financial obligations that come with families or even aging parents, the underground art world presents challenges to the artists in it. Thus, the answer to this question is dependent on other lifestyle choices outside of the immediate culture surrounding the production of art.

Finally, considering the challenges offered by aging, I asked, Are these artists permanent residents of the underground subcultural world? In other words, do they plan participation in their underground world for the long haul? Much of the answer to this question lies in speculation. My observational evidence does not support aging and staying in the subculture, as most of the participants were young. However, this may be misleading considering that the underground culture has only grown over the last decade or so. Jason, the member of OPS whose story is featured in extended format in chapter 
two, is a testament to the ability for artists to stay in the subculture regardless of age. He still maintains some part time work while supporting his art career, and is regularly involved in the underground, as he has been since the early 1990's. He cites the strong social networks of support that he has with many people who have been participants in DIY culture for as many years as he has. Members indicate a strong willingness to continue their involvement in underground art, and their participation so far indicates a successful future for the group.

The challenge presented by long-term participation is financial rather than maturational as members have no intention of transitioning to the established art world as their reputation grows. This is a culture that supports art making and requires only time from its participants. My projection is that long term participation likely depends on how adaptable artists can be to changing financial obligations.

\section{Suggestions for Change in Art School Curriculum}

To prepare for art after school, teach cooperative support

Portland's DIY subculture is a large and regionally specific contributor to the cooperative nature of the underground art world. This contribution is likely not easily spread outside of this region, but the other source of cooperative culture generation, art school, deserves some attention. Although cooperative culture seems to develop naturally in art schools or art programs, I suggest a more explicit approach to fostering cooperative behavior in school. Fine arts programs should teach cooperative support as part of preparation for graduation. As students near the end of their program and develop cooperation naturally, programs should acknowledge this development. Teaching the benefits of continued cooperative support is a way to create a better transition for artists 
after school since it helps to ensure continued art making and social support and networks that aid artists in doing their work. From teaching the benefits of working collaboratively to living in an art neighborhood, information about cooperation can only help artists and grow underground art worlds.

Teach the difference between the established and grow awareness

Furthermore, although many programs prepare their students to enter the established art world through teaching portfolio skills and methods for gaining entry into galleries, students should also be made explicitly aware of the possibilities outside of the established art world. While it is certainly helpful to teach students gallery skills, all students cannot fit through competitive funnel that the established art world operates with. Using Becker's concept of Art Worlds as a frame it is important to teach artists about the social reality of the art world that they are preparing for. Becker is right to suggest that knowing about art required studying the social structure that enables production, and teaching artists this is a tool for empowerment.

My proposal is to integrate instruction about how underground art worlds operate, in addition to providing information about where healthy underground art worlds are. An awareness of this alternative way of doing art is likely to help some students who may become discouraged by competition. Rather than giving up their art practice, students may be able to find a supportive community that will help them to do their work.

Providing information about the differences between underground art culture and established art world culture will also help students to access the established world. Rather than running into barriers based in a lack of understanding about how to appeal to the established art world, a knowledge based in a comparison between the two art worlds 
might make it easier for students to interpret expectations. Conversely, it would also aid artists in understanding what to expect from both worlds, leaving students empowered with knowledge.

\section{Limitations of Study}

This study contains two major limitations. First, because this is a single case, it is difficult to know generalizable the findings might be for Portland artists. A comparative case study of another collective in Portland would verify that the interactions OPS has with the underground art world are typical. However, OPS's descriptions of neighborhood involvement, and their central location in the arts district indicate that their story is part of a larger reality for artists in Portland. Also, the recent proliferation of artist collectives is apparent in news media (The Oregonian 2008-2009; Willamette Weekly 2008- 2009; Portland Mercury 2008- 2009) suggests that there are several active groups in the area.

Second, because Portland is a city known for its exceptional personality, it is difficult to project if an underground art world in another city would look the same as Portland's underground. However, stories and studies in the UK and other US cities such as Chicago and New York describe similar a cultural presence (Bradley, 2004, Lloyd, 2004). It is likely that while regional cultural differences exist, the underground art world in similar cities would resemble Portland in features and neighborhood location.

\section{Future Research: Migratory Patterns and Semi-peripheral Cities}

This project supports the theory that semi-peripheral cities provide a different opportunity structure for artists from the established world. This is new because the focus on art worlds has been on placed that are core art cities. It is important in continuing 
research to explore the benefits of semi-peripheral art worlds and their underground cultures in order to develop a strong knowledge about how artists do their work.

Further research should identify semi-peripheral art cities. A qualitative comparative analysis of underground art culture in semi-peripheral cities would expand the understanding about how art worlds function, and make explicit the regional differences between semi-peripheral art worlds. Comparative analysis would also shed light on how different city neighborhoods and amenities are able to contribute to artistic development. This is important for artists since it can provide them more information about how to best support their work and themselves. Additionally, it is useful information for cities who wish to attract or grow more art culture since art reputation can also attract other creative class citizens as Florida suggests.

Finally, a study of migratory patterns of graduating artists would help to shed light on who is drawn to underground art worlds. Rather than relying on national reports, a study that tracks students after graduation would give a valid indication about the direction of art world development. Especially in economic recession, learning where artists go to make their work would help to identify what artists value outside of an economic structure. Additionally, since the Internet provides the ability for artists to represent themselves rather than relying on a gallery, it is possible that art worlds may be transitioning to a more decentralized model than the national hierarchical established model that is prominent now. If DIY values surrounding production of art are able to support artists they might opt out of the competitive model that is counter-intuitive to their natural cultural development. The detachment of income from career work is an 
unusual instance worth studying. In the case of Portland, artists are choosing a healthy cooperative culture over the possibility of competitive economic success. 


\section{References:}

Becker, H. 1982. Art Worlds. Berkeley: University of California Press

Blazak, R. 1991. “The Rise and Fall of Bohemian Enclaves: A World System View.” Pp. 107-19 in Cities in the World System, ed. Resat Kasaba. New York: Greenwood Press.

Bradley, P. 2004. "Enjoy the Ride" Capital \& Class. 84:179

Charmaz, K. 2006. Constructing Grounded Theory: A Practical Guide Through

Qualitative Analysis. Los Angeles: Sage.

Evergreen State College. “Academics” Retrieved October 15th, 2011. (http:// www.evergreen.edu/academics.htm)

Florida, R. 2002. The Rise of the Creative Class. New York: Basic Books

Foster, L. 2008. Portland City Walks. Portland: Timber Press.

Friends of Last Thursday. "Last Thursday: The Nexus Where Art \& People Meet!" Retrieved on October 20, 2011. (http://www.lastthursdayonalberta.com/)

Hebdige, D. 1979. Subculture and the Meaning of Style. London: Routledge.

"Helsing Junction Farm's Sleepover. 3 days of Music, Film, and Art." Community Events, Helsing Junction Farm. Retrieved October 15, 2011.(http://helsingfarmcsa.com/community-events.php)

Heying, C. 2010. Brew To Bikes. Portland: Ooligan Press.

K Records. “How Did K Records Start?” Retrieved October 15, 2011. (http://www.krecs.com/html/info/)

Jurjevich, J. 2011. “A Pivot Point? Economic Slow-down Affects Oregon's 
Migration Flow" Population Research Center, Portland State University.

Retrieved October 20, 2011. (http://mkn.research.pdx.edu/2011/05/slow-

economy-tempered-oregon-population-growth-over-decade/)

Lloyd, R. 2004. "The Neighborhood in Cultural Production: Material and Symbolic Resources in New Bohemia." City \& Community 3: 343-371

Marshall, C., \& Rossman, G. 2006. Designing Qualitative Research. Thousand Oaks: Sage.

The Oregonian, online. 2009. "search terms: 'artist collective' 2008-2009".

Retrieved on November 23, 2009. The Oregonian (available www.oregonlive.com/oregonian/)

Oregon Painting Society. "PROJECTS" and "PRESS" Retrieved February 15th, 2011. (http://www.oregonpaintingsociety.org/)

Pariser, E. 2000. "Artists' Websites: Declarations of Identity and Presentations of Self," in D. Gauntlett (ed.) Web. Studies. New York: Arnold.

Portland Art Dealer's Association "First Thursday Art Walk: 25-Year Tradition Continues to Grow" October 6. Retrieved on October 20, 2011. (http://padaoregon.org/sites/default/files/downloads/FirstThurs_25yrs_0.pdf)

Portland Mercury, online. 2009. "search terms: 'artist collective' 2008-2009". Retrieved on November 23, 2009. The Portland Mercury (available at www.portlandmercury.com/2

Prey, D. 1996. Hype. [DVD]. Los Angeles: Helvey-Pray Productions

Row, D.K. 2010. “Portland's Art Galleries Adapt to a Changing World After the Great Recession" The Oregonian, April 23. Retrieved November 21, 2011. (http:// 
Www.oregonlive.com/art/index.ssf/2010/04/portlands_art_galleries_adapt.html)

Row, D.K. 2011. "The Rise and Fall of Last Thursday” The Oregonian, February 25. Retrieved October 19, 2011. (http://www.oregonlive.com/art/index.ssf/2010/02/ commentary_the_rise_and_fall_o.html)

Dominic, H. 2000. Shield around the K. [DVD] Olympia: Independently Produced by Heather Rose Dominic, Marguerite Ruscito, and Paul Seff.

Shaw, S., \& Sullivan, D. 2011. “'White Night': Gentrification, Racial Exclusion, and Perceptions and Participation in the Arts." City \& Community 10: 241-264.

Shorthose, J. and Strange, G. 2004. "The New Cultural Economy, the Artist and the Social Configuration of Autonomy" Capital \& Class. 84:43.

Shorthose, J. 2004. "The Engineered and the Vernacular in Cultural Quarter Development" Capital \& Class. 84: 159.

Siu, V. 2010. “Percent Change in Population, Oregon Counties, 2000-2010.” Population Research Center, Portland State University. Retrieved October 20, 2011. (http://pdx.edu/sites/www.pdx.edu.profiles/PopChgMap.jpg).

Smith, J. 2004. Social Movements for Global Democracy. Baltimore: The Johns Hopkins University Press

Strickland, G. "Catch that Beat!". The Portland Mercury. August 4, 2006. Retrieved October 15th, 2011, (http://www.portlandmercury.com/portland/Content? oid=53977\&category $=22153$ )

Turner, C. 2001. The Riot Grrl Movement: the Feminism of a New Generation. New York: The Rosen Publishing Group 
Uzzi, B. 1996. "The Consequences of Embeddedness for Economic Performance of Organizations: The Network Effect.” American Sociological Review 4: 674-698.

Putnam, R. 2000. Bowling Alone: The Collapse and Revival of American Community.

New York: Simon and Schuster.

Willamette Week, online. 2009. "search terms: 'artist collective' 2008-2009"

Retrieved on November 23, 2009. Willamette Week (available www.wweek.com)

MacKaye, Ian. 2006. “History” Retrieved on October 15, 2011.

(http://www.dischord.com/history/)

Wikipedia a., "Alternative Tentacles". (n.d.) Wikipedia. Retrieved October 15th, 2011. (http://en.wikipedia.org/wiki/Alternative_Tentacles)

Wikipedia b., "Bikini Kill”. (n.d.) Wikipedia. Retrieved October 15th, 2011. (http:// en.wikipedia.org/wiki/Bikini_Kill)

Wikipedia c., "Calvin Johnson”. (n.d.) Wikipedia. Retrieved October 15th, 2011. (http:// en.wikipedia.org/wiki/Calvin_Johnson_(musician))

Wikipedia d., "Dead Kennedys”. (n.d.) Wikipedia. Retrieved October 15th, 2011. (http:// en.wikipedia.org/wiki/Dead_Kennedys)

Wikipedia e., "Fan Zine”. (n.d.) Wikipedia. Retrieved October 15, 2011. (http:// en.wikipedia.org/wiki/Fanzine)

Wikipedia f., “"Fugazi”. (n.d.) Wikipedia. Retrieved October 15, 2011. (http://en.wikipedia.org/wiki/Fugazi)

Wikipedia g., "Grunge”. (n.d.) Wikipedia. Retrieved October 152011. (http://en.wikipedia.org/wiki/Grunge)

Wikipedia h., "Heavens to Besty". (n.d.) Wikipedia. Retrieved October 15th, 2011. 
(http://en.wikipedia.org/wiki/Heavens_to_betsy)

Wikipedia i., "What the Heck fest". (n.d.) Wikipedia. Retrieved October 15th, 2011. (http:// en.wikipedia.org/wiki/What_The_Heck_Fest)

Wikipedia j., "Ian Svenonius". (n.d.) Wikipedia. Retrieved October 15th, 2011. (http:// en.wikipedia.org/wiki/Ian_Svenonius)

Wikipedia k., "International Pop Underground". (n.d.) Wikipedia. Retrieved October 15th, 2011. (http://en.wikipedia.org/wiki/International_Pop_Underground_Convention)

Wikipedia 1., "Ladyfest". (n.d.) Wikipedia. Retrieved October 15th, 2011.(http:// en.wikipedia.org/wiki/Ladyfest)

Wikipedia m., "Sleater Kinney”. (n.d.) Wikipedia. Retrieved October 15th, 2011. (http:// en.wikipedia.org/wiki/Sleater-Kinney)

Wikipedia n., "YACHT". (n.d.) Wikipedia. Retrieved October 15th, 2011. (http:// en.wikipedia.www.org/wiki/YACHT) 


\section{Appendix A. Artist Collective Interview Guide}

Just to start out, I want to know a little about your story.

1. Before OPS, and other than OPS work, what kinds of art do you do?

2. What does being an artist mean to you?

3. Do you consider yourself a professional artist? Why or why not?

Now I want to talk about a little about OPS in particular,

4. Can you tell me a little about how you were involved in forming OPS?

5. How did OPS decide to become a collective as opposed to, for instance, remaining individual artists?

a. Probes: trial and error, did you interact with another collective?

6. How would you describe the way OPS is organized, or how you learned to work together?

a. Probes: Does everyone pull an equal amount of weight? Do you have different roles?

7. What does being a part of OPS and working with people close to you do for your art and your social life?

a. Probes: your artistic production? Your artistic identity? Social time?

8. Can you describe how OPS is integrated into the rest of your priorities?

a. Probes: How much time to you work doing OPS projects versus other art or other work? How do you make a living?

9. What do you think, if anything, OPS does for your personal artistic career?

Probes: Do you have a bigger network for showing your work? Do you have a better support network?

I am also interested in knowing who your audience is.

10. Who do you think comes to see OPS projects and do you think your audience was different before you were working with OPS?

a. Probes: Other artists? gallery goers?

11. How do people find out about your shows?

a. Probes: new people vs. those who have already seen your work? 
I am also really interested in the way OPS networks. I wonder,

12. What kind of place would you say you typically have performances, exhibitions, shows, etc.? What other art is shown there? What kinds of galleries are there? What is the difference between them?

13. How do you think you get more shows?

a. Probes: Other Artists, Reputation (if so, how do you get it?), People who attend the show, People who own the Venues, Reviews in Papers

14. How do you fund new projects? Do you make money at shows?

15. Does OPS often work or arrange shows with other artists? Why or why not?

16. Do you think that competition with other artists or groups plays any role in how OPS works?

a. Probes: Do you feel competition with other artists for space? Reputation? Audience?

17. Here is a diagram I am working on about how art worlds work.

a. This diagram (show Becker's commercial gallery) shows the established Art World. Do you think this is an accurate representation? Why or Why not?

b. This diagram shows the underground art world. Do you think this is an accurate representation? Why or why not?

c. What are the differences between the underground art world and the established art world?

18. Finally, is there anything you think that I am missing that you would like to tell me?

Things to follow up during observation:

How does a project happen from beginning to the end? What parts am I missing? What role do found supplies play? 


\section{Appendix B. Art Venue Interview Guide}

$4 / 19 / 11$

First of all, I am interested in how artists decide how to do their art work. Are you an artist? What do you do?

Could you tell me your story about how your gallery was founded?

I read your mission statement, how did you decide what purposes your gallery would serve?

How do you find people to exhibit/perform/ sell?

Why is your gallery a good place for artists to show their work?

Is your gallery a typical gallery? How is it different? Do you feel competition with other galleries like yours?

Is Portland a good place to do art? Why or why not? 


\section{Appendix C. Participant Observation Consent Form}

\section{Portland State University, Sociology Department}

You are invited to participate in a research study conducted by Elizabeth Borders from Portland State University, Sociology department. The researcher hopes to learn how artists who have organized into collectives live as a partial fulfillment of a master's degree under the supervision of Professor Robert Liebman. You were selected as a possible participant in this study because you are an artist in an artist collective that the researcher is studying.

If you decide to participate, the researcher will spend about one month of time with your collective at events or other activities that your collective does in order to observe how your collective functions. The purpose of this observation will be to understand what being in your collective is like. The observation will take place wherever your collective meets, or at any events your collective participates in or hosts. The researcher will take notes and sometimes audio-record her observations for her records. Before any audiorecording, the researcher will inform you that she will be recording. Sometimes the researcher may ask you questions about her observations. Keep in mind that if you ever feel uncomfortable with the researcher being present, you can simply request that she leave. You may also share any information, verbally or written, with the researcher during or after the observation period that you would like to add to her observations. You may also request to see the researcher's notes taken during observation of you. You may not receive any direct benefit from taking part in this study, but the study may help to increase knowledge which may help other artists in the future.

Any information that is obtained in connection with this study and that can be linked to you or identify you will be kept confidential, except that you will be identified as a member of your collective. This information will be kept confidential in audio and text files on a password protected computer and in a locked office after the transcription of your interview is complete. The interviewer will complete all transcriptions.

Keep in mind that your participation is voluntary. You do not have to take part in this study, and it will not affect your relationship with Portland State University. You may also withdraw from this study at any time without affecting your relationship with Portland State University.

If you have concerns or problems about your participation in this study or your rights as a research subject, please contact the Human Subjects Research Review Committee, Office of Research and Sponsored Projects, 600 Unitus Bldg., Portland State University, (503) 725-4288 / 1-877-480-4400. If you have questions about the study itself, contact Elizabeth Borders at (859) 420-8626.

Your signature indicates that you have read and understand the above information and agree to take part in this study. Please understand that you may withdraw your consent at 
any time without penalty, and that, by signing, you are not waiving any legal claims, rights or remedies. The researcher will provide you with a copy of this form for your own records.

Signature

Date

**Limits to confidentiality must be stated clearly, as well. The State of Oregon requires that all suspected or confirmed cases of child and elder abuse must be reported to authorities, and subjects must be informed of this limit if the nature of the research makes it likely that such a topic will be discussed. 


\section{Appendix D. Collective Member Interview Consent Form}

\section{Portland State University, Sociology Department}

You are invited to participate in a research study conducted by Elizabeth Borders from Portland State University, Sociology department. The researcher hopes to learn how artists who have organized into collectives live as a partial fulfillment of a master's degree under the supervision of Professor Robert Liebman. You were selected as a possible participant in this study because you are an artist in an artist collective that the researcher is studying.

If you decide to participate, you will be asked to complete an interview lasting for about one hour and answer questions concerning how you feel about living in or as a part of an artist collective. The purpose of this interview will be to both verify what I have learned during my time with you, and for you to explain your perspective about being an artist in a collective. The interview will take place at Portland State University, Cramer Hall, room $217 \mathrm{C}$ and will be audio-recorded for the researcher's records. Although the researcher does not foresee any questions as sensitive, keep in mind that if you ever feel uncomfortable answering any questions, you can simply not answer them. You may not receive any direct benefit from taking part in this study, but the study may help to increase knowledge which may help other artists in the future.

Any information that is obtained in connection with this study and that can be linked to you or identify you will be kept confidential, except that you will be identified as a member of your collective. This information will be kept confidential in audio and text files on a password protected computer and in a locked office after the transcription of your interview is complete. The interviewer will complete all transcriptions.

Keep in mind that your participation is voluntary. You do not have to take part in this study, and it will not affect your relationship with Portland State University. You may also withdraw from this study at any time without affecting your relationship with Portland State University.

If you have concerns or problems about your participation in this study or your rights as a research subject, please contact the Human Subjects Research Review Committee, Office of Research and Sponsored Projects, 600 Unitus Bldg., Portland State University, (503) 725-4288 / 1-877-480-4400. If you have questions about the study itself, contact Elizabeth Borders at (859) 420-8626.

Your signature indicates that you have read and understand the above information and agree to take part in this study. Please understand that you may withdraw your consent at any time without penalty, and that, by signing, you are not waiving any legal claims, rights or remedies. The researcher will provide you with a copy of this form for your own records. 
Signature

Date

**Limits to confidentiality must be stated clearly, as well. The State of Oregon requires that all suspected or confirmed cases of child and elder abuse must be reported to authorities, and subjects must be informed of this limit if the nature of the research makes it likely that such a topic will be discussed. 


\section{Appendix E. Art Venue Interview Consent Form}

\section{Portland State University, Sociology Department}

You are invited to participate in a research study conducted by Elizabeth Borders from Portland State University, Sociology department. The researcher hopes to learn how artists who have organized into collectives show their work as a partial fulfillment of a master's degree under the supervision of Bob Liebman. You were selected as a possible participant in this study because you are a venue where an artist collective that the researcher is studying has shown work.

If you decide to participate, you will be asked to complete an interview lasting for about one hour and answer questions concerning how your venue thinks about showing art. The purpose of this interview will be for you to explain your perspective about showing artwork. The interview will take place at your venue and will be audio-recorded for the researcher's records. Although the researcher does not foresee any questions as sensitive, keep in mind that if you ever feel uncomfortable answering any questions, you can simply not answer them. You may not receive any direct benefit from taking part in this study, but the study may help to increase knowledge which may help other artists in the future.

Any information that is obtained in connection with this study and that can be linked to you or identify you will be kept confidential, except that you will be identified as someone who runs a venue. This information will be kept confidential in audio and text files on a password protected computer and in a locked office after the transcription of your interview is complete. The interviewer will complete all transcriptions.

Keep in mind that your participation is voluntary. You do not have to take part in this study, and it will not affect your relationship with Portland State University. You may also withdraw from this study at any time without affecting your relationship with Portland State University.

If you have concerns or problems about your participation in this study or your rights as a research subject, please contact the Human Subjects Research Review Committee, Office of Research and Sponsored Projects, 600 Unitus Bldg., Portland State University, (503) 725-4288 / 1-877-480-4400. If you have questions about the study itself, contact Elizabeth Borders at (859) 420-8626.

Your signature indicates that you have read and understand the above information and agree to take part in this study. Please understand that you may withdraw your consent at any time without penalty, and that, by signing, you are not waiving any legal claims, rights or remedies. The researcher will provide you with a copy of this form for your own records. 
Signature

Date

**Limits to confidentiality must be stated clearly, as well. The State of Oregon requires that all suspected or confirmed cases of child and elder abuse must be reported to authorities, and subjects must be informed of this limit if the nature of the research makes it likely that such a topic will be discussed. 